
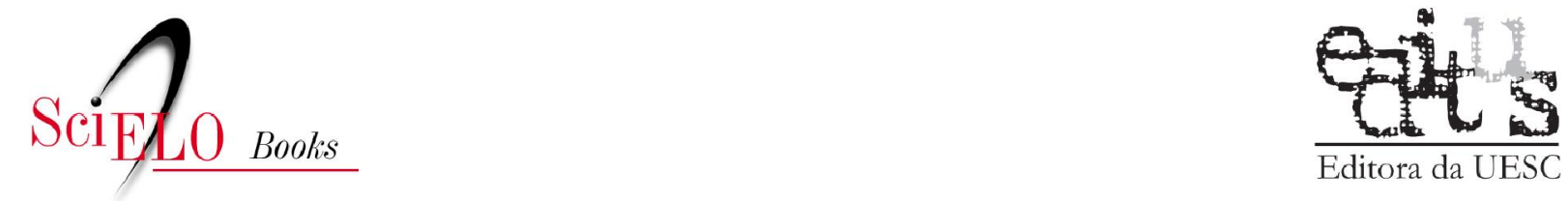

Editora da UESC

\title{
14 - Notas sobre interações competitivas envolvendo formigas poneromorfas
}

\author{
Rogerio Silvestre \\ Paulo Robson de Souza \\ Gabriel Santos Silva \\ Bhrenno Maykon Trad \\ Vinicius Marques Lopez
}

SILVESTRE, R., et al. Notas sobre interações competitivas envolvendo formigas poneromorfas. In: DELABIE, JHC., et al., orgs. As formigas poneromorfas do Brasil [online]. Ilhéus, BA: Editus, 2015,

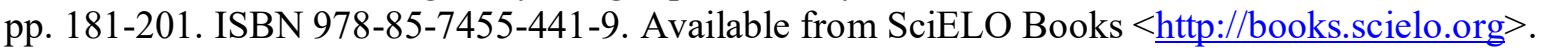

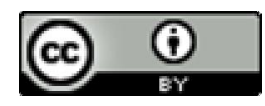

All the contents of this work, except where otherwise noted, is licensed under a Creative Commons Attribution $\underline{4.0 \text { International license. }}$

Todo o conteúdo deste trabalho, exceto quando houver ressalva, é publicado sob a licença Creative Commons Atribição 4.0 .

Todo el contenido de esta obra, excepto donde se indique lo contrario, está bajo licencia de la licencia $\underline{\text { Creative }}$ Commons Reconocimento 4.0. 


\title{
Notas sobre interações competitivas envolvendo formigas poneromorfas
}

\author{
Rogerio Silvestre, Paulo Robson de Souza, Gabriel Santos Silva, \\ Bhrenno Maykon Trad, Vinicius Marques Lopez
}

\section{Resumo}

Toda interpretação de protocolos de observações do comportamento animal vem recheada de antropomorfismos; contudo os registros observados têm um sentido mais amplo visto aos olhos de um especialista, que pode dar ressignificados a conceitos pré-estabelecidos e reinterpretar certos comportamentos que aparentemente têm intenções determinadas, mas que muitas vezes podem ser respostas a algo não visível ou mensurável pelo observador. Visualizar e analisar atos comportamentais de ação e reação de Hymenoptera no campo não é uma tarefa simples de ser feita e exige muita percepção, previsibilidade, imaginação e até mesmo sorte, todos, é claro, sentidos humanos, que limitam nossa interação com a natureza.

Neste capítulo apresentamos uma série de notas de comportamentos obtidas em campo de interações interespecíficas envolvendo formigas poneromorfas, na tentativa de responder quais são os competidores em potencial para este grupo de espécies tratadas na literatura como "formigas caçadoras"; analisando, assim, como este agrupamento artificial, de espécies com ecologias similares, interage no espaço e tempo, sobrepondo os seus nichos ecológicos e compartilhando recursos com outras espécies de formigas sintópicas.
Partimos do pressuposto de que pelo fato de as formigas poneromorfas epigeicas serem na maioria predadoras solitárias e patrulharem grandes áreas ao redor do ninho, elas seriam competidoras entre si, compondo desta forma uma guilda de espécies predadoras solitárias grandes, na qual, neste universo, seria passível de serem observadas interações agonísticas entre as espécies que co-ocorrem na mesma área. Contudo, isto é extremamente raro de ser observado e fotografado em campo. Fotografar atos comportamentais se torna ainda mais difícil no campo porque além de sorte é necessário técnica. O esforço desta tarefa é muito dispendioso, pois um ato comportamental que leva poucos segundos tem que ser capturado pela lente, sendo o comportamento congelado na fotografia.

Este texto é um apanhado de notas de cadernos de campo e da análise de dezenas de vídeos e de centenas de registros fotográficos de observações de campo de vários anos de pesquisa. Aqui tratamos de discutir qual a dinâmica de visitação em iscas atrativas e quais estratégias comportamentais são empregadas pelas formigas poneromorfas em interações interespecíficas.

SILVESTRE, Rogerio; SOUZA, Paulo Robson de; SILVA, Gabriel Santos; TRAD, Bhrenno Maykon; LOPEZ, Vinicius Marques. Notas sobre interações competitivas envolvendo formigas poneromorfas. In: DELABIE, Jacques H. C. et al. As formigas poneromorfas do Brasil. Ilhéus: Editus, 2015. p. 181-201. 
Observations on competitive interactions involving poneromorph ants - We present a series of behavioural observations obtained from field observations concerning interspecific interactions of poneromorph ants in an attempt to answer what the potential competitors for this group of ants are. We analysed this using artificial groupings of species with similar ecologies, interacting in space and time, overlapping in their ecological niches and sharing resources with other species of syntopic ants. Observation and analysis of behavioural actions and reactions of Hymenoptera in the field is not a simple task and requires a lot of insight, predictability, imagination and even luck. However, in the eyes of an expert, the observed records can provide new meanings to pre-established concepts and allow reinterpretation of certain behaviours. This can often provide answers to something that is not visible or measurable by the observer. The records analysed were made by the authors at different times, over more than twenty years. We applied field observation protocols at various sites in Brazil, including the Cerrado vegetation types, Deciduous Forest, Pantanal, Caatinga, Chaco and Atlantic Rainforest. The discontinuous periods of field expeditions totalled approximately 200 hours of observation. Several interactions were filmed and photographed successfully during this period, and hundreds of field notes were amassed. The first phenomenon that we investigated was the existence of interspecific aggressive behaviour at baits, against a backdrop of direct competition for the established resource. We then categorized the observed behavioural acts into action and reaction of interacting species. When we found dominance at the food supply, we investigated how it took place? We asked what behavioural categories, foraging strategies and morphological traits would be involved in those interactions that resulted in dominance at baits and subsequent exclusion of other species? Another issue that we investigated is whether one species is always dominant, regardless of which species are present at the same bait. At approximately half of the baits observed, interspecific aggression was observed. Our results indicate that a more persistent resource is not a prerogative for certain behaviourally aggressive species, and they may also employ other important strategies in this context, for example, mass recruitment. Although poneromorphs are usually aggressive predators, they are seldom dominant at baits, possibly due to them having individual foraging strategies or tandem recruitment. However, they often visit the food source and collect food, even in the presence of other species. The fact that poneromorphs are generally large allows them to obtain a comparable amount of food to that of species with massive recruitment capabilities. Diversification in the diet of these ants induces niche overlap, which, in tropical environments with high spatial heterogeneity, allows the coexistence of different resource-sharing strategies. The epigaeic species of Ponerinae, Ectatomminae and Paraponerinae, seem to clearly establish their foraging areas, recognizing those enemies that are in the same morpho-functional space, thus avoiding contact and dispute over food supply; in other words, they recognize their "intimate enemies". Our results suggest that dominance is related to certain situations favouring one or other species. We conclude that in tropical environments there is no pre-established dominance hierarchy, as reported in temperate environments and that a very large number of ecological, physiological and spatial variables is influencing the competitive interactions involving poneromorph ants.

\section{Estratégias de forrageamento e a competição por recursos}

Devido a sua forma de organização, seu hábito oportunista e a grande diversidade de espécies coexistindo numa mesma área, muitas espécies compartilham recursos e sobrepõem seus nichos ecológicos; desta forma, a competição é frequentemente observada entre operárias de espécies de formigas (GREENSLADE, 1982). A competição é apontada por Dobzhanski (1950) e Hölldobler; Wilson (1990) como sendo determinante para definir a estrutura da comunidade local.

Como as formigas são insetos sociais, o resultado das interações interespecíficas dependerá de características tanto em nível da colônia como 
no nível do indivíduo, e a vitória desta disputa entre duas colônias ou operárias de diferentes espécies pode depender de características tais como o tamanho corporal, a morfologia, a presença de um aparato de ferrão, ou de outras características fisiológicas associadas a este contexto, como a defesa química por exemplo. Assimetrias podem resultar de diferenças numéricas com base no tamanho da colônia ou da localização do ninho, ou habilidades de recrutamento em diferentes escalas (MORRISON, 2000).

$\mathrm{Na}$ competição por alimento, as formigas utilizam um rico repertório de técnicas de forrageamento, sendo um dos mais comuns a monopolização do território onde a colônia explora o recurso. A patrulha da área de caça e a contínua vigilância da fonte de alimento têm o sentido de prevenir o acesso de outras espécies ao recurso, inclusive de operárias da mesma espécie oriundas de diferentes colônias. Zinck et al. (2008) correlacionaram significativamente a distância geográfica e a agressividade na interação intraespecífica entre colônias poligínicas e polidômicas de Ectatomma tuberculatum (Olivier, 1792), sugerindo que ambos sinais genéticos e ambientais podem estar envolvidos no reconhecimento dos mecanismos de discriminação das companheiras de ninho.

As espécies que utilizam o recrutamento massivo e a agressividade têm chances de dominar a fonte de alimento e excluir outras espécies (HUNT, 1974; TRANIELLO, 1989; SILVESTRE, 1995). A aptidão em explorar o hábitat para a obtenção do alimento está associada à capacidade de aprendizagem e experiência das operárias, ao tipo de orientação empregado (se químico ou visual), às morfologias especializadas, à distância da entrada do ninho em relação ao tipo de recurso utilizado, ao estresse térmico, à quantidade e qualidade dos alimentos e ao status nutricional e sazonalidade da colônia (BERNSTEIN, 1975; LEVINGS; TRANIELLO, 1981; OVERAL, 1986; BRANDÃO et al., 2000; GUÉNARD; SILVERMAN, 2011). Bred et al. (1987) e Fewell et al. (1996) demonstraram em seus estudos com Paraponera clavata (Fabricius, 1775) que respostas graduais de comportamento e eventuais mudanças na estratégia de recrutamento aparecem dependendo da qualidade nutricional do recurso utilizado e da distância da fonte alimentar em relação ao ninho.

A razão de depósito de marcas químicas, a persistência em uma determinada direção, a atração a novas fontes e trilhas, o efeito da concentra- ção do feromônio no recrutamento, além de propriedades como a razão de evaporação das marcas, temperatura e a velocidade de locomoção das operárias forrageando, são fatores determinantes no comportamento de resposta de grupo (HUNT, 1974; HAGEN et al., 1984; MOUTINHO, 1991; EDELSTEIN-KESHET et al., 1995).

Torres (1984), estudando a coexistência de espécies de formigas em comunidades de Porto Rico, tenta responder se as espécies que têm seus nichos sobrepostos com o de outras tenderiam a ser mais agressivas. Seus resultados indicam que agressões entre formigas de espécies diferentes são menos frequentes em áreas florestadas quando comparadas a áreas cobertas por outras formações, incluindo agroecossistemas, sugerindo que agressões interespecíficas nas fontes alimentares prevalecem em habitats com estruturas menos heterogêneas, e que nem sempre a sobreposição de nichos induz à agressividade.

A conduta agressiva é normalmente associada ao comportamento territorial, mas muitas espécies de formigas evitam o dispêndio de energia de uma competição direta empregando outras estratégias menos custosas do que a agressividade como, por exemplo, a segregação temporal e espacial, o uso de combates ritualizados, ou utilizando estratégias diferentes de forrageamento (PASSERA; ARON, 2006).

Levings (1983) discute o emprego da flexibilidade e territorialidade na procura e obtenção do alimento pelas formigas de uma comunidade e conclui que uma espécie provavelmente interage com muitas outras com requisitos ecológicos similares ao longo do tempo, o que pode resultar em dois efeitos seletivos opostos: na especialização, que reduz o número de espécies interativas e na alta flexibilidade e generalidade no comportamento, que aumentariam a probabilidade de contingências.

Contudo, nem só competindo vivem as formigas e muitas interações harmônicas e mutualísticas também podem ser observadas em campo.

\section{Protocolo de observações de campo}

Os registros analisados foram obtidos por meio de uma série de observações de campo, realizadas pelos autores, em diferentes épocas, com registros esparsos realizados em mais de vinte anos de coletas de informações comportamentais de espécies de formigas. Realizamos protocolos 
de observações de campo em diversas localidades cobertas com as fitofisionomias representadas de Cerrado, Floresta Estacional Decidual, Pantanal, Caatinga e Mata Atlântica (Tabela 14.I). Somados os períodos descontínuos de observações de campo, totalizamos aproximadamente 200 horas analisadas. Várias interações foram filmadas e fotografadas com sucesso neste período, dentre centenas de registros.

Analisamos as notas dos protocolos de observações onde houve interações competitivas envolvendo formigas "poneromorfas" das subfamílias Ponerinae, Paraponerinae e Ectatomminae, principalmente em iscas atrativas; sendo a maior parte elaborada com sardinha em óleo comestível, mimetizando fontes de proteína e de gordura; além disso, também foram empregados outros itens como, atum, mel, carne, arroz e insetos mortos ou vivos imobilizados como, por exemplo, um gafanhoto com as pernas arrancadas, besouros, taquarinhas, dípteros, etc; também utilizamos como iscas atrativas pequenos lambaris e minhocas na beira do rio. As iscas foram distribuídas no solo (sobre o folhiço ou sobre pedra), ficando expostas pelo período de 90 a 100 minutos, dependendo do observador (noventa por cento dos registros analisados foram retirados dos cadernos de campo do primeiro autor).

A primeira questão que investigamos foi a existência de comportamentos agressivos interespecíficos na disputa pelas iscas oferecidas, com um cenário de competição direta pelo recurso estabelecido; em seguida, organizamos uma categorização dos atos comportamentais observados separados em ação e reação das espécies interagentes. Quando constatada a dominância na fonte alimentar, como ela ocorria? Que categorias comportamentais, estratégias de forrageamento e determinantes morfológicos estariam envolvidos nas interações que resultaram na dominância e exclusão de espécies da isca? Outra questão que investigamos é se uma determinada espécie é sempre dominante independentemente de quais espécies estão presentes na mesma isca.

Consideramos dominante, neste estudo, como o fato de uma espécie exercer uma ação que deprecie a atividade das outras, reduzindo ou excluindo outras espécies da fonte alimentar, seja por agressividade ou por abundância, ou ambos. Tratamos frequência, abundância e dominância como variáveis distintas nesta pesquisa. Neste caso, consideramos como: frequente, a espécie que obteve um número elevado de registros em iscas; abundante, a espécie que tem um grande número de indivíduos forrageando nas iscas; e dominante, a espécie que venceu um cenário competitivo estabelecido.

Apenas as observações que seguiram um protocolo padronizado nas localidades indicadas na Tabela 14.I foram analisadas quantitativamente; sendo que alguns registros fotográficos de observações esparsas feitas em ambientes no Pantanal e na Mata Atlântica foram utilizados neste capítulo no sentido de ilustrar determinados comportamentos, mas não entraram na análise.

Estabelecemos critérios para categorizar as espécies nas iscas quanto à dominância e quanto ao número de indivíduos presentes em intervalos de tempo pré-estabelecidos. Tomamos também uma medida de tamanho relativa das operárias de espécies participantes das interações onde houve dominância, para avaliar o efeito do tamanho nas ordens de dominância observadas em cada isca.

Categorizamos os atos comportamentais exibidos por espécies que participaram das interações e em seguida somamos os critérios gerando conjuntos de 3 pares de números cada, que representam as síndromes comportamentais exibidas em cada evento em que uma espécie de formiga Poneromorfa foi observada interagindo com outras espécies nas iscas; sendo dessa forma possível ordenar as espécies comportamentalmente dentro das interações.

TABELA 14.I - Localidades onde foram realizadas observações de interações envolvendo formigas poneromorfas em iscas atrativas.

\begin{tabular}{l|l|l|l}
\hline Localidades & Período & Fitofisionomia & Coordenadas \\
\hline Fazenda Santa Carlota Cajuru- SP & 1992,1993 & Cerrado/Cerradão & $21^{\circ} 27^{\prime} \mathrm{S}-47^{\circ} 20^{\prime} \mathrm{W}$ \\
\hline Estação Ecológica Jataí- Luís Antônio- SP & 1995,1996 & Cerradão & $21^{\circ} 36^{\prime} \mathrm{S}-47^{\circ} 47^{\prime} \mathrm{W}$ \\
\hline RPPN Cara da Onça, Rio Salobra, Bodoquena- MS & $2009,2013,2014$ & $\begin{array}{l}\text { Mata Estacional } \\
\text { Decidual }\end{array}$ & $20^{\circ} 44^{\prime} \mathrm{S}-56^{\circ} 44^{\prime} \mathrm{W}$ \\
\hline Campus da UFMS, Campo Grande- MS & 2013,2014 & Cerrado & $20^{\circ} 30^{\prime} \mathrm{S}-54^{\circ} 36^{\prime} \mathrm{W}$ \\
\hline Flona Contendas do Sincorá- BA & 2014 & Caatinga & $13^{\circ} 55^{\prime} \mathrm{S}-41^{\circ} 06^{\prime} \mathrm{W}$ \\
\hline
\end{tabular}


Para correlacionarmos o tamanho da espécie com a agressividade, consideramos tamanho como variável independente e agressividade como variável dependente. Para analisar a influência do tamanho das espécies na exclusão das iscas, consideramos o tamanho como variável independente e a exclusão como variável dependente. Nossa hipótese nula é de que a agressividade e a exclusão não estariam relacionadas ao tamanho das espécies interagentes.

\section{Categorias comportamentais}

Os atos comportamentais exibidos pelas espécies que visitaram as iscas e que interagiram agressivamente foram divididos em ação e reação e assim interpretados:

\section{Ação}

1. Avançar = ir em direção ao indivíduo de outra espécie com as mandíbulas abertas, num movimento abrupto, antropomorficamente interpretado como uma forma de ameaça.

2. Morder = agarrar com as mandíbulas partes do corpo do outro indivíduo por alguns instantes.

3. Roubar a isca $=$ retirar a isca do indivíduo que a carregava.

4. Exibir a região do ferrão ou ferroar $=$ virar o gáster para baixo do ventre, muitas vezes exibindo o aparelho de ferrão.

5. Levantar o gáster $=$ agitar o gáster, aparentemente expelindo químicos repelentes.

6. Matar $=$ Agressões que resultaram na morte do indivíduo agredido.

\section{Reação}

1. Permanecer $=0$ indivíduo não sai da arena de alimentação mesmo depois de agredido.

2. Fugir $=o$ indivíduo agredido deixa a isca rapidamente.

3. Ferroar $=o$ agressor é ferroado como resposta a agressão.

4. Levantar o gáster $=$ expelir feromônio em resposta à agressão.

5. Lutar $=$ os dois indivíduos engajam-se em "disputa corpórea".

6. Matar $=\mathrm{o}$ indivíduo agredido, neste caso, mata $\mathrm{o}$ agressor.

Cada espécie de formiga poneromorfa registrada nas observações de campo foi também classificada em categorias que expressavam o seu comportamento em relação ao tipo de dominância; sendo definidos dois parâmetros para avaliação: o primeiro relativo ao tipo de interação, que indica principalmente a dominância ou exclusão da fonte alimentar e o segundo relativo ao fluxo dos indivíduos que cada espécie apresentou durante a visitação às iscas.

\section{Classificação dos tipos de Dominância e Exclusão}

1.0 - A não dominância (as espécies consideradas não dominantes foram aquelas que, na maioria das interações em que se envolveram, não interferiram na obtenção do alimento e nem no fluxo das outras espécies que visitaram as mesmas iscas).

1.1 - A dominância da isca realizada por agressividade.

1.2 - A dominância da isca realizada por abundância.

1.3 - A exclusão da isca (foi considerada excluída a espécie que ocupava a isca durante a observação e ao final desta teve seu fluxo reduzido à zero, devido à presença de uma espécie dominante; aplicamos a mesma denominação àquelas espécies que foram impedidas de chegar à isca).

\section{Fluxo de Indivíduos}

2.0 - Exclusivo: um único indivíduo presente durante o tempo de observação.

2.1 - Fraco: de 2 a 10 visitas realizadas à isca durante o período de observação (podendo ou não ser o mesmo indivíduo contabilizado).

2.2 - Médio: de 11 até 30 indivíduos visitaram a isca.

2.3 - Intenso: mais de 30 indivíduos visitaram a isca nos 90-100 minutos de observação.

Esta classificação de dominância possibilitou a ordenação do comportamento em conjuntos de números que indicam: o primeiro par, os tipos de dominância; o segundo par, a intensidade do fluxo dos indivíduos durante a visitação a isca; e o terceiro par, a frequência das categorias em relação ao número total de registros obtidos. Por exemplo: o conjunto [1.1],[2.2],[3/3] significa que esta espécie dominou por ser agressiva, com um fluxo de indivíduos na isca considerado médio, sendo que esta síndrome aconteceu três vezes nas três oportunidades 
TABELA 14.II - Representação das categorias comportamentais para 17 espécies de formigas poneromorfas observadas visitando as iscas atrativas. Obs: $1^{\circ}$ par indica o tipo de dominância; o $2^{\circ}$ par indica o fluxo de indivíduos visitando a isca durante o período de observação; $3^{\circ}$ par indica o número de vezes em que um determinado comportamento foi observado dentro do total do número de registros obtidos para a espécie.

\begin{tabular}{|c|c|c|c|}
\hline Dinoponera australis & \begin{tabular}{|l}
{$[1.0],[2.0],[9 / 12]$} \\
{$[1.0],[2.1],[1 / 12]$} \\
{$[1.3],[2.0],[2 / 12]$}
\end{tabular} & Neoponera villosa & $\begin{array}{l}{[1.0],[2.0],[1 / 9]} \\
{[1.0],[2.1],[4 / 9]} \\
{[1.3],[2.0],[2 / 9]} \\
{[1.3],[2.3],[2 / 9]}\end{array}$ \\
\hline Dinoponera quadriceps & \begin{tabular}{|l|}
{$[1.0],[2.1],[6 / 18]$} \\
{$[1.0],[2.2],[6 / 18]$} \\
{$[1.0],[2.3],[6 / 18]$} \\
\end{tabular} & Odontomachus bauri & {$[1.0],[2.1],[2 / 2]$} \\
\hline Ectatomma edentatum & $\begin{array}{l}{[1.0],[2.0],[2 / 14]} \\
{[1.0],[2.1],[10 / 14]} \\
{[1.0],[2.3],[2 / 14]}\end{array}$ & Odontomachus chelifer & $\begin{array}{l}{[1.0],[2.0],[2 / 7]} \\
{[1.0],[2.1],[2 / 7]} \\
{[1.1],[2.0],[1 / 7]} \\
{[1.3],[2.0],[2 / 7]}\end{array}$ \\
\hline Ectatomma brunneum & \begin{tabular}{|l}
{$[1.0],[2.1],[3 / 5]$} \\
{$[1.0],[2.2],[1 / 5]$} \\
{$[1.3],[2.2],[1 / 5]$}
\end{tabular} & Odontomachus haematodus & $\begin{array}{l}{[1.0],[2.2],[1 / 2]} \\
{[1.1],[2.1],[1 / 2]}\end{array}$ \\
\hline Ectatomma permagnum & $\begin{array}{l}{[1.0],[2.1],[3 / 4]} \\
{[1.3],[2.1],[1 / 4]} \\
\end{array}$ & Odontomachus meinerti & {$[1.0],[2.1],[1 / 1]$} \\
\hline \multirow{2}{*}{ Mayaponera constricta } & \multirow{2}{*}[1.0]{$,[2.1],[2 / 2]$} & Pachycondyla harpax & {$[1.0],[2.0],[2 / 4]$} \\
\hline & & Pachycondyla impressa & {$[1.0],[2.0],[1 / 1]$} \\
\hline Neoponera apicalis & $\begin{array}{l}{[1.0],[2.0],[1 / 2]} \\
{[1.0],[2.1],[1 / 2]}\end{array}$ & Pachycondyla striata & $\begin{array}{l}{[1.0],[2.0],[2 / 4]} \\
{[1.0],[2.1],[1 / 4]} \\
{[1.0],[2.2],[1 / 4]}\end{array}$ \\
\hline Neoponera obscuricornis & \begin{tabular}{|l}
{$[1.0],[2.1],[6 / 12]$} \\
{$[1.0],[2.2],[1 / 12]$} \\
{$[1.0],[2.3],[3 / 12]$} \\
{$[1.3],[2.1],[2 / 12]$}
\end{tabular} & Paraponera clavata & $\begin{array}{l}{[1.0],[2.1],[2 / 4]} \\
{[1.1],[2.1],[1 / 4]} \\
{[1.2],[2.3],[1 / 4]}\end{array}$ \\
\hline
\end{tabular}

em que a espécie foi observada; enquanto o conjunto [1.0],[2.3],[1/6] significa que esta espécie não dominou a isca, que o recrutamento foi massivo (fluxo intenso) e que este comportamento ocorreu apenas uma vez nas seis oportunidades em que a espécie foi registrada (frequência absoluta) (Tabela 14.II).

\section{Resultados e discussão das interações compiladas}

A sobreposição dos períodos de atividade e de áreas de forrageamento por espécies de formigas poneromorfas que visitaram a mesma fonte alimentar (iscas) foi observada nas localidades estudadas, assim como em outros estudos realizados em outros ambientes (PETAL, 1978; ANDERSEN, 1986; HÖLLDOBLER, 1987).

Foram registrados atos comportamentais de dezessete espécies de poneromorfas nos protocolos de observações de 90-100 minutos, em mais de 200 iscas avaliadas no período nas localidades estudadas: Dinoponera australis Emery, 1901; Dinoponera quadriceps Kempf, 1971; Ectatomma brunneum Smith, F., 1858; E. edentatum Roger, 1863; E. permagnum Forel, 1908; Mayaponera constricta (Emery, 1884); Neoponera apicalis
(Latreille, 1802); N. villosa (Fabricius, 1804); N. obscuricornis (Emery, 1890); Odontomachus bauri Emery, 1892; O. chelifer (Latreille, 1802); O. haematodus (Linnaeus, 1758); O. meinerti Mann, 1912; Pachycondyla harpax (Fabricius, 1804); P. impressa (Roger, 1861); P. striata Smith, F., 1858 e Paraponera clavata (Fabricius, 1775) e duas espécies foram fotografadas em uma observação esporádica que não consta nas análises: Ectatomma planidens Borgmeier, 1939 e E. opaciventre (Roger, 1861), interagindo em Corumbá, no Pantanal, na disputa por uma formiga Camponotus rufipes morta (Ver Figura 13.3 do capítulo 13).

Analisando a participação do grupo "poneromorfas" no cenário global das notas de interações compiladas, verificamos que houve a visitação por pelo menos uma espécie de formiga poneromorfa em 103 das 200 iscas consideradas; e interações agonísticas envolvendo disputa por recurso ocorreram em $40 \%$ das iscas com o envolvimento das poneromorfas.

Em aproximadamente metade das iscas observadas, agressões interespecíficas foram verificadas. As agressões provocadas por formigas poneromorfas ocasionaram a morte de um ou 
mais indivíduos de outra espécie em 20 iscas observadas, neste caso a morte foi provocada em 15 oportunidades como um ato de ação (ou seja, uma espécie poneromorfa agrediu outra espécie assim que chegou à isca) e em cinco oportunidades como reação (ou seja, uma espécie poneromorfa matou outro indivíduo de outra espécie em resposta a agressão sofrida).

Como ação, os atos mais comuns empregados pelas formigas poneromorfas foram avançar (60\% dos registros) e morder (30\% dos registros), e como reação fugir da isca foi a resposta comportamental das formigas poneromorfas em $75 \%$ dos casos.

A dominância só foi observada 4 vezes envolvendo Odontomachus chelifer (1 isca), $O$. haematodus (1) e Paraponera clavata (2). Mesmo em alguns casos onde alguns indivíduos de Odontomachus dominaram a porção superior da isca, agrediram e excluíram outras espécies, a visitação a porção inferior da isca por espécies minúsculas não foi impedida.

Os resultados das análises correlação de tamanho e agressividade apontam para uma relação positiva, ou seja, espécies maiores tendem a ser mais agressivas $(p=0,03)$. Já para os resultados analisados sobre a exclusão da isca, a hipótese nula (independência entre exclusão ou não da isca e o tamanho) não foi rejeitada (teste exato de Fisher= 0,47- uni-caudal) Isto é, apesar de espécies de tamanho relativamente grande serem mais agressivas, isto não significa que excluem consistentemente outras espécies menores da fonte alimentar.

Em 95\% das observações realizadas envolvendo poneromorfas a primeira espécie destas que localizou a isca não foi a mais abundante ao final do período de observação ou exerceu um papel de dominante. Brandão et al. (2000) mostram que $85 \%$ das espécies encontram a isca de sardinha nos primeiros cinco minutos de exposição no Cerrado, sendo registradas em média 4,8 espécies visitando o mesmo recurso e que até nove espécies de formigas podem ser encontradas em uma mesma isca, sendo a sucessão de dominância do recurso intensa.

A Figura 14.1 apresenta dois exemplos da sucessão de dominância em iscas onde houve interação competitiva entre espécies, ilustrando a frequência de registros em intervalos de 15 minutos para as espécies Pachycondyla striata e Neoponera villosa no Cerrado do estado de São Paulo.
A ordem de chegada das espécies à isca não está necessariamente associada ao seu domínio. A "dominância" de uma fonte alimentar por uma espécie de formiga parece estar associada à distância da fonte ao ninho, ao tamanho da colônia, à estratégia de forrageamento, ao local, época e período de atividade preferencial e principalmente à atratividade do alimento e status nutricional em que as colônias das espécies interagentes se encontram no momento.

A constância do recurso influencia sobremaneira o panorama da interação. Foi observado em várias oportunidades o esgotamento da isca carregada aos pedaços ao ninho antes do final do período de observação. Foi muito frequente observar besouros, moscas, lagartas e minhocas, utilizadas como iscas, imediatamente serem transportadas para o ninho por uma operária poneromorfa antes que a isca pudesse ser localizada por outra espécie. É bastante expressiva a preferência das espécies de poneromorfas, que patrulham a superfície do solo, por este tipo de recurso efêmero (curta duração). Gomes et al. 2009 avaliaram a dinâmica de forrageamento de Ectatomma brunneum, utilizando dípteros como iscas, e concluíram que diferenças no comportamento observado em condições de campo sugerem uma expressiva flexibilidade de estratégias adotadas, e isto pode variar de acordo com o nível da competição, o tamanho e peso da presa.

A variação da dieta foi observada para a maioria das espécies aqui estudadas, sendo isto comumente observado para formigas Ponerinae, Paraponerinae e Ectatomminae (GIANNOTTI; MACHADO, 1992; EHMER; HÖLLDOBLER, 1996; PIE, 2004; RAIMUNDO et al., 2009; TOFOLO et al., 2011; LIMA; ANTONIALLI-JUNIOR, 2013). Muitas espécies utilizam matéria vegetal, exibem a necrofagia ou executam a caça solitária em diferentes proporções, com o uso de anelídeos e vários artrópodos na dieta como Insecta, Crustacea, Chylopoda, Diplopoda, Arachnida, etc., sendo a dieta também composta por formigas. Medeiros e Oliveira (2009) estudaram o forrageamento de Pachycondyla striata e observaram que esta espécie emprega o comportamento de varredura de área de maneira solitária ou em grupo, coletando insetos mortos em mais de $80 \%$ da frequência dos registros, a caça solitária (10\%), e a associação com outras espécies e o cleptoparasitismo, em $10 \%$ dos registros obtidos.

Nossos resultados indicam que o domínio de recursos mais persistentes (média duração) não 
é prerrogativa de determinadas espécies comportamentalmente agressivas, mas de espécies que empregam também outras estratégias importantes nesse contexto, como, por exemplo, o recrutamento em massa. As Ponerinae apesar de serem geralmente predadoras agressivas, quase nunca dominaram a isca, possivelmente devido à estratégia individual de forrageamento ou o recrutamento em tandem running que empregam; entretanto quase sempre atingiram a fonte alimentar e coletaram alimento, mesmo na presença de outras espécies. $\mathrm{O}$ fato de as poneromorfas serem grandes faz com que elas sejam capazes de obter uma quantidade de alimento comparável àquelas espécies pequenas de recrutamento massivo. Quase sempre que confrontadas com espécies que utilizam estratégias de recrutamento massivo nas iscas, as poneromorfas conseguem retirar pedaços relativamente grandes da sardinha e carregá-los ao ninho; é necessário um número bem maior de indivíduos de uma espécie pequena, trabalhando por muito mais tempo, para coletar a mesma quantidade de alimento que indivíduos isolados relativamente maiores carregam; o que praticamente equipara o custo/

FIGURA 14.1 - Dois exemplos da dinâmica de visitação em iscas por P. striata e N. villosa expostas no solo do Cerrado por 90 minutos, as quais foram dominadas por outras espécies e cuja interação resultou na exclusão parcial ou total da fonte de alimento de outros visitantes.
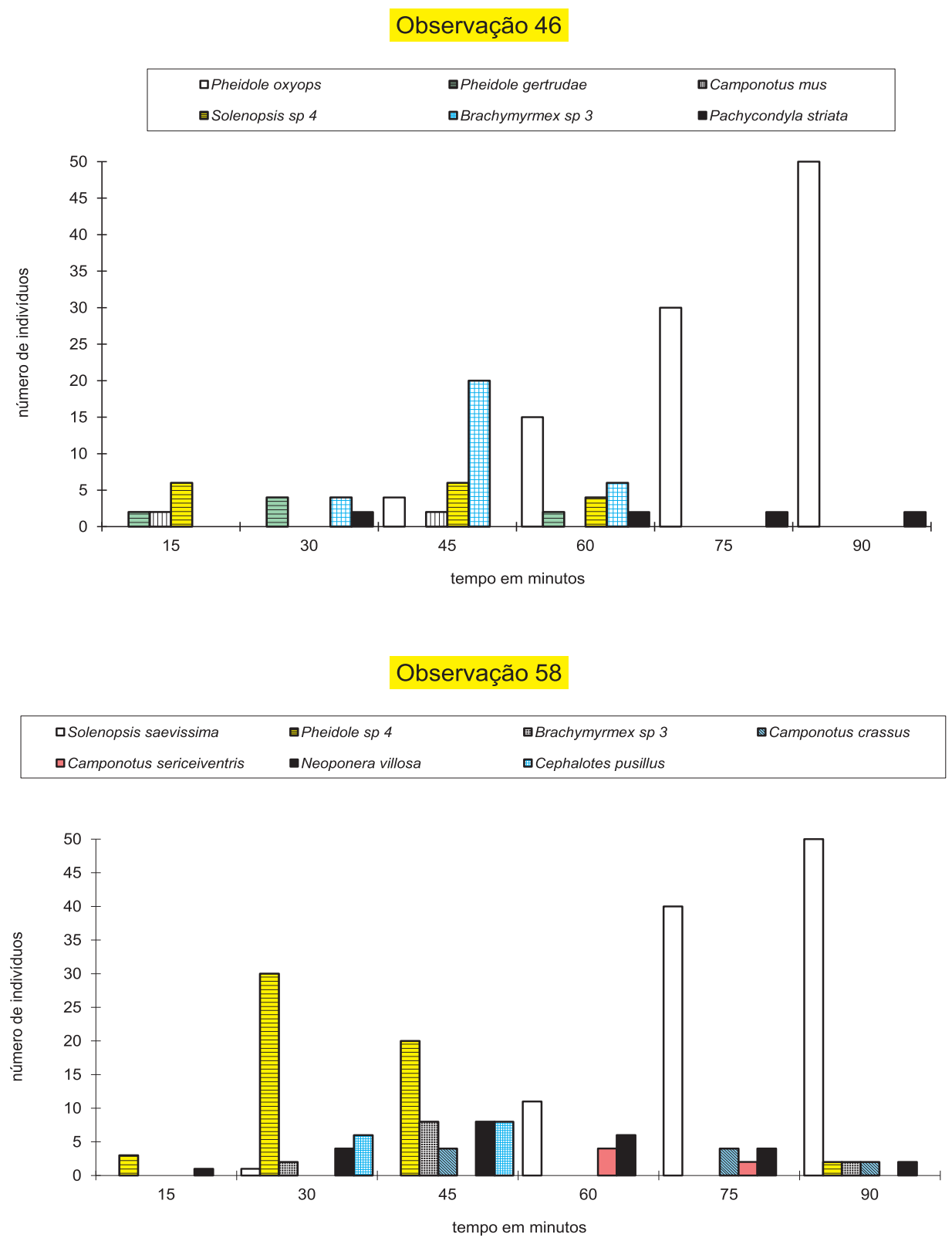
benefício em relação à quantidade de alimento capturado por espécie.

No apêndice 14.1 fazemos a transcrição resumida de uma observação realizada no Cerrado envolvendo espécies de poneromorfas para que o leitor tenha uma noção da forma como foram registrados os comportamentos em iscas e da dinâmica de visitação das várias espécies que interagiram numa isca.

Nossos resultados nos fazem acreditar que não existe uma condição hierárquica de dominância pré-estabelecida nos tipos de habitats onde foram realizadas as observações; e sim que certas situações favoreçam ora uma espécie ora outra. Para as espécies em que o comportamento de domínio da isca parece estar associado à agressividade, o resultado da interação dependeu de com quais espécies ela interagiu. Por exemplo, algumas espécies agressivas não impediram o fluxo das que frequentavam a porção ventral do papel que continha a sardinha. $\mathrm{Na}$ análise por pares de espécies que competem pela sardinha foi verificado que uma delas pode dominar a isca comportamentalmente excluindo ou impedindo o acesso da outra à fonte em uma oportunidade, mas em outra ocasião a situação inversa pode ocorrer, isto é, a que havia dominado age agora como subordinada. Este foi o caso de Odontomachus chelifer, que foi excluída por Camponotus crassus em uma ocasião, mas a excluiu em outra. Existem casos em que a exclusão de uma espécie ocorreu mais de uma vez na isca e casos em que a dominância foi mudada ao longo do tempo; isto é, uma espécie excluiu outra da isca e dominou totalmente o recurso por um tempo e antes do final da observação também foi excluída por uma terceira.

Em determinadas ocasiões, uma espécie pode aumentar a rapidez com que coleta o alimento, podendo usar a fonte de alimento antes de serem deslocadas por outras mais agressivas ou abundantes. Em várias oportunidades foi registrado o comportamento de espreita, quando uma operária, por exemplo, Ectatomma permagnum, fica parada próxima à isca que está colonizada por outra espécie, esperando um momento de aproximação "menos ariscado" para acessar a sardinha.

Os registros obtidos indicam que a guilda de predadores grandes de recrutamento solitário ou aos pares (tandem running) consegue um sucesso maior na obtenção de alimento, superando os possíveis competidores de recrutamento massivo, que apresentam polimorfismo de castas, quando o recurso pode ser carregado assim que localizado, como um inseto morto ou moribundo. Neste caso, as poneromorfas atuam como oportunistas e assim que encontram um artrópodo morto, o transportam para o ninho, antes das outras espécies o encontrarem; mas se outras espécies o localizaram primeiro vai haver competição se uma poneromorfa também chegar.

Pouquíssimas vezes foram observadas interações entre espécies de poneromorfas nas iscas. Comportamentos ritualizados foram observados entre duas espécies que se encontraram rapidamente sobre a isca, não havendo registro de disputa corpórea efetiva (lutas). Também foi observada uma única vez no Cerrado a agressão (talvez por engano) entre dois espécimes de Odontomachus bauri, oriundos da mesma colônia, em meio a vários outros indivíduos de Crematogaster que expeliam químicos dobrando o gáster para cima. Após se agredirem, pareceu que os indivíduos perceberam que não se tratava de um inimigo.

\section{DESCRITIVO dos comportamentos observados das espécies de formigas poneromorfas fotografadas em iscas atrativas}

\section{Dinoponera australis}

Foi observada interagindo com outras espécies em 12 ocasiões. Na maioria dos registros ela foi atraída com insetos parcialmente imobilizados (bicho pau, dípteros, besouros e lagartas de lepidópteros) e minhocas. Agrediu e mordeu algumas operárias de Solenopsis sp. quando capturava um tabanídeo morto e as Solenopsis tentavam arrastá -lo em grupo. Em iscas de sardinha retiram pedaços mesmo colonizada por outras espécies. Fugir da isca foi o comportamento mais comum observado e a resposta à agressão mais comum foi morder e ferroar. O máximo de indivíduos frequentando a mesma isca foi de quatro operárias, mas porque a isca estava próxima ao ninho; normalmente são visitantes isolados que chegam na isca. Foi excluída em uma ocasião das proximidades da isca quando foi atacada por dezenas de operárias de Pheidole oxyops Forel, 1908 que dominavam o recurso alimentar; em outra oportunidade, em colônias monitoradas na RPPN Cara da Onça, interagiu agressivamente com Pheidole radoszkowskii Mayr, 1884 e Pheidole fimbriata Roger, 1863 tentando ferroar e morder as Pheidole (Figura 14.2). Apresentam interação mutualística com Pheidole dinophila Wilson, 2003 que também visitam a sardinha e outros recursos quando colocados próximos à entrada do 
FIGURA 14.2 (A e B) - Dinoponera australis em interação com Pheidole na RPPN Cara da Onça, Bodoquena, MS.

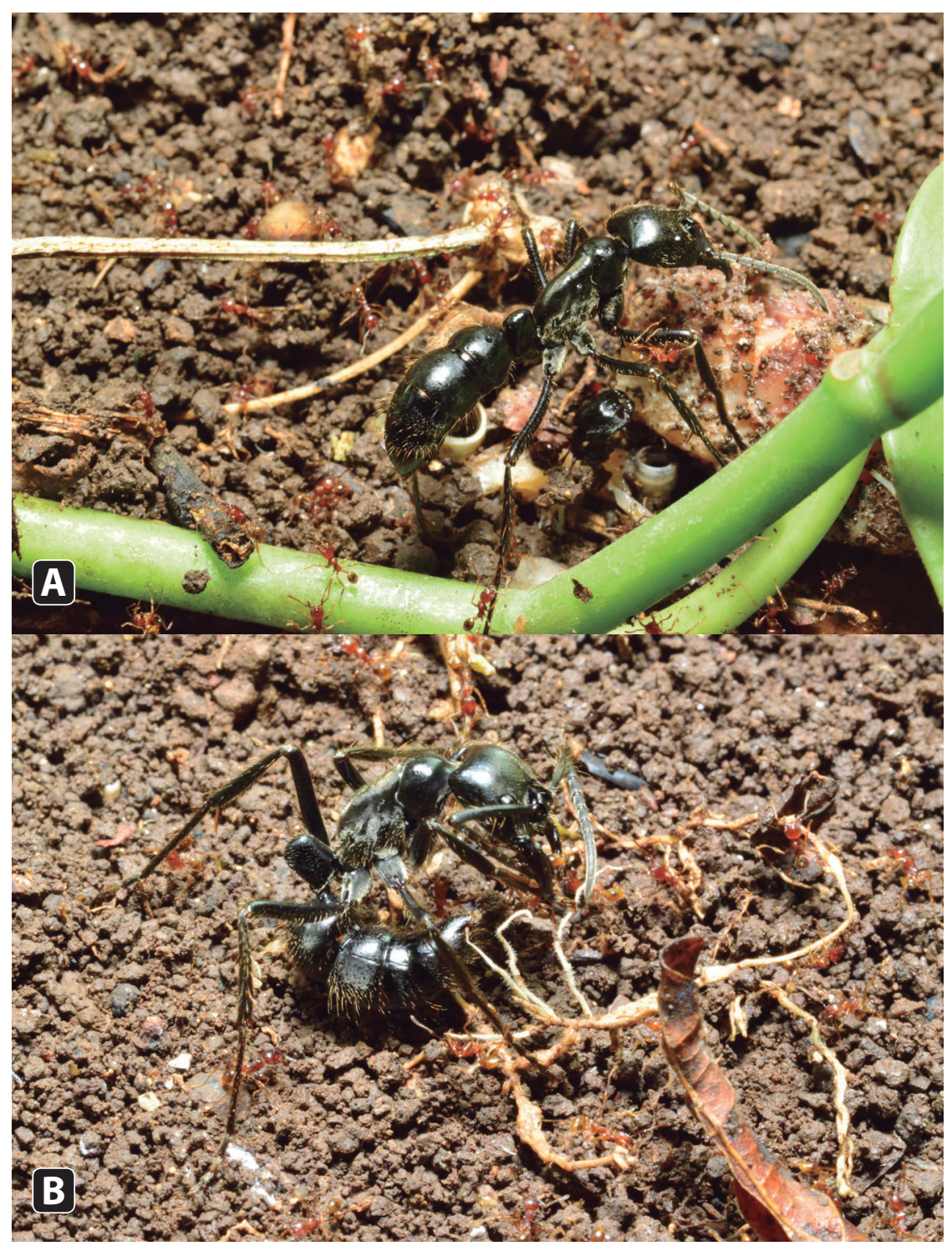

ninho. Estão ativas durante o dia, mas a atividade noturna é muito intensa. A abertura do ninho de D. australis estudado na Serra da Bodoquena mede $78 \mathrm{~mm}$ de largura por $30 \mathrm{~mm}$ de altura em média, sendo sempre feito embaixo de pedra de calcário. Foi observado, nesta localidade, um exemplar de $D$. australis transportando um pequeno anfíbio vivo, Rhinella scitula (Caramaschi; Niemeyer, 2003) endêmico da região, em comportamento de tanatose. Ao soltar o anfíbio para localizar o ninho, o mesmo escapou da predação com um pulo.

\section{Dinoponera quadriceps}

Uma das espécies de formigas encontradas na Caatinga no Nordeste brasileiro nas observações realizadas na Floresta Nacional Contendas do Sincorá (FNCS) no estado da Bahia. Os ninhos encontrados na FNCS são construídos logo abaixo dos troncos de árvores vivas, apresentando uma abertura grande recoberta por pequenos galhos. Em alguns casos, foram observados ninhos com mais de uma abertura próximas uma da outra (menos de um metro). As observações indicam que a competição intraespecífica pelo espaço entre os ninhos pode não ser um fator limitante para essa espécie. Em muitos casos foi possível observar gamergates de até três colônias diferentes de $D$. quadriceps interagindo na mesma isca. Durante as observações feitas na FNCS, alguns indivíduos de $D$. quadriceps mostraram comportamentos agressivos ao encontrarem formigas da mesma espécie de ninhos diferentes 
atraídos pelas iscas. Apesar disso, os indivíduos recém-chegados às iscas nunca foram expulsos e nunca sofreram danos ou houve casos de mortes observados entre os indivíduos envolvidos nessas disputas. Quando os encontros ocorriam, as duas operárias de ninhos diferentes agiam de forma ritualizada e se afastavam em direções opostas e, após alguns segundos, retornavam com o mesmo comportamento de forrageio em direção à isca e uma voltava a avançar sobre a outra.

D. quadriceps foi observada interagindo com diversas outras espécies de formigas coexistentes na FNCS. As principais espécies de formigas atraídas pelas iscas de sardinha foram: Camponotus atriceps (Smith, F., 1858), Dorymyrmex pyramicus (Roger, 1863), Eciton quadriglume (Haliday, 1836), Ectatomma edentatum Roger, 1863, Labidus coecus (Latreille, 1802), Neivamyrmex pilosus (Smith, F., 1858), Odontomachus bauri Emery, 1892, Pheidole flavens Roger 1863, Pheidole obscurithorax Naves 1985, Pheidole triconstricta Forel, 1886, Forelius sp., Camponotus blandus (Smith, F., 1858), Camponotus melanoticus Emery, 1894, Camponotus senex
(Smith, F., 1858) e Camponotus vittatus Forel, 1904. Mesmo diante de espécies agressivas que dominam completamente as iscas, a $D$. quadriceps não se intimidam e nunca são permanentemente excluídas da fonte de alimento (Figura 14.3).

Durante o estudo foi possível observar indivíduos de $D$. quadriceps andando por cima de uma grande quantidade de indivíduos da espécie Labidus coecus até chegar à isca e conseguir retirar parte do recurso disponível, sem serem impedidos, mesmo diante de tantas ferroadas e mordidas desferidas pelas operárias de L. coecus (Figura 14.4).

Em cada observação feita com as iscas atrativas foi possível contabilizar uma média de três a quatro formigas por ninho forrageando nas iscas. De 31 observações realizadas nesta área esta espécie visitou 18 delas e foram contabilizados 87 ninhos de D. quadriceps envolvidos nas iscas. Apesar de Araújo; Rodrigues (2006) mostrarem que o forrageio de Dinoponera quadriceps é sempre individual, não ocorrendo recrutamento em nenhuma ocasião, foi registrado em Contendas do Sincorá até quatro indivíduos da mesma colônia

FIGURA 14.3 - Dinoponera quadriceps interagindo com Camponotus vittatus na Caatinga da Flona Contendas do Sincorá-Bahia.

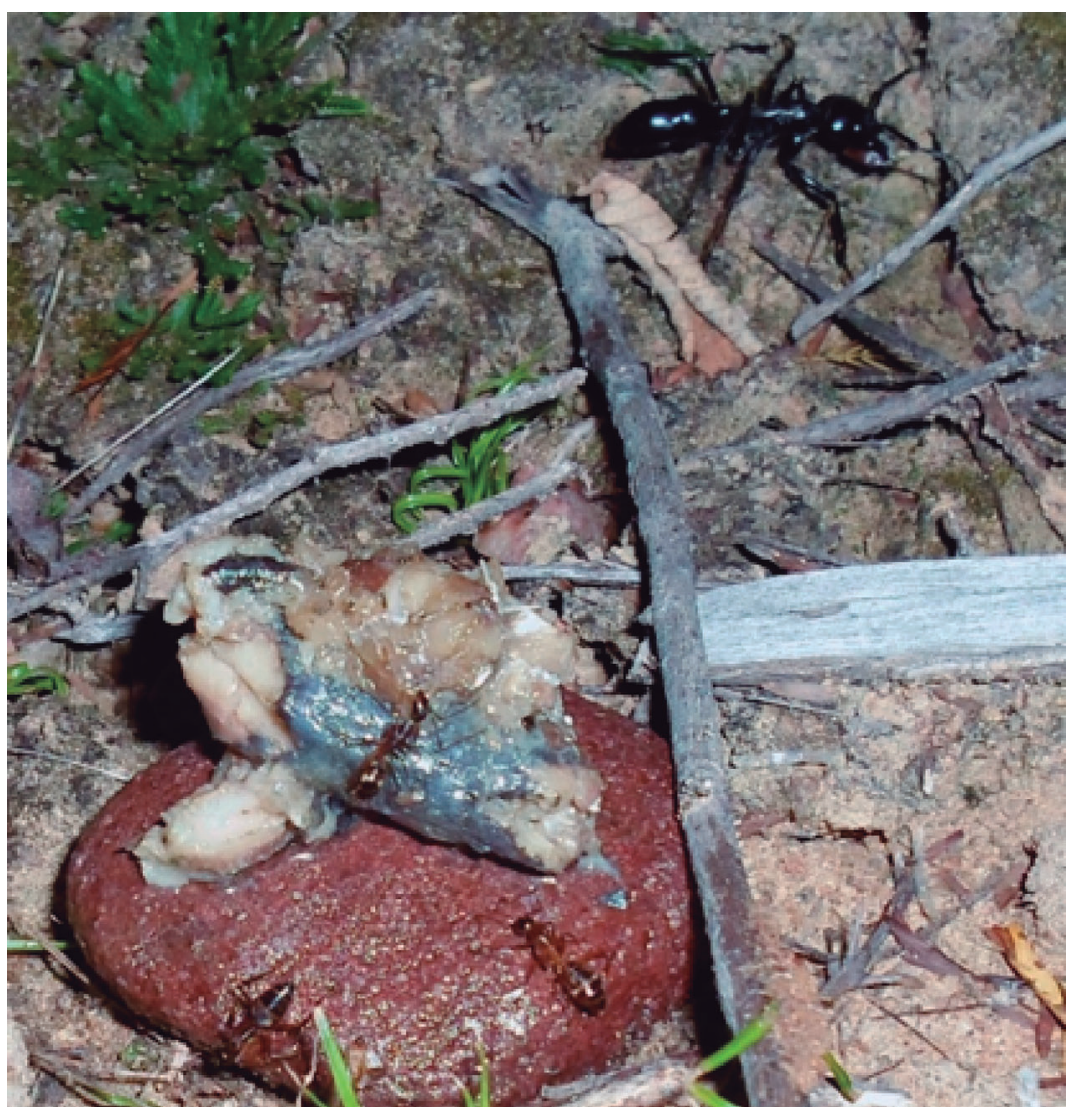


FIGURA 14.4 - Dinoponera quadriceps e Labidus coecus na Caatinga da Flona Contendas do Sincorá- Bahia.

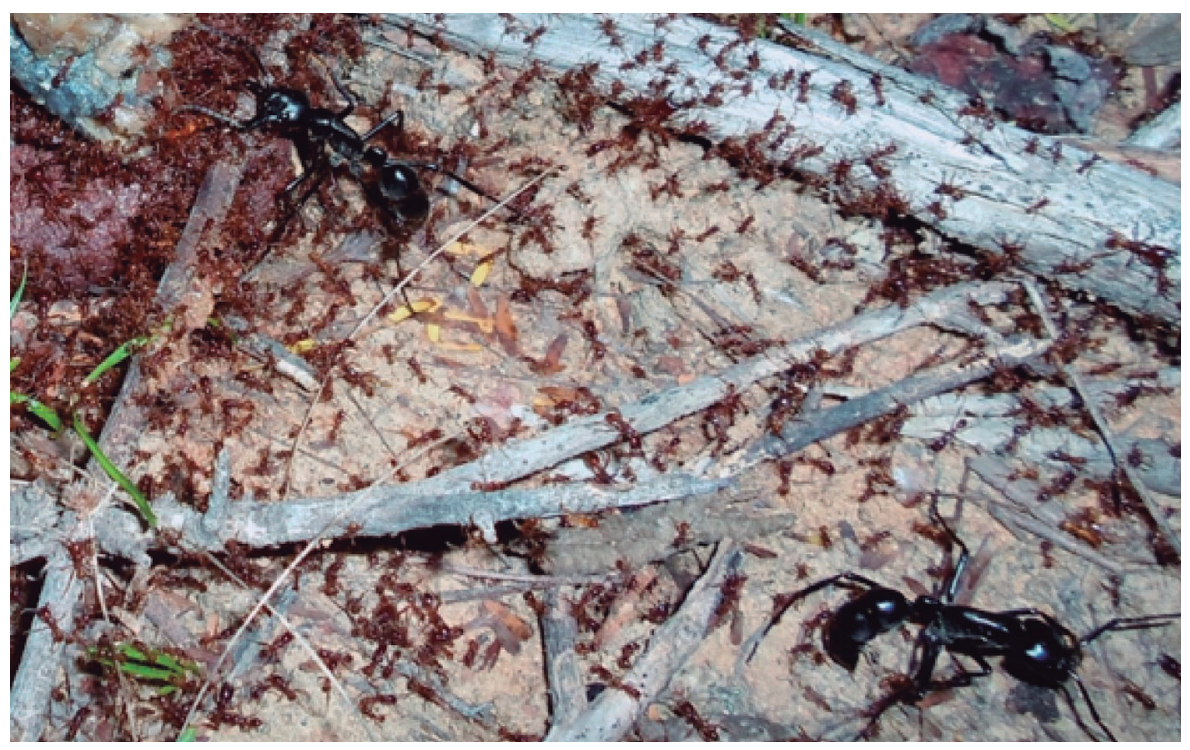

FIGURA 14.5 - Paraponera clavata predando um Orthoptera no chão de uma área de Cerrado em Mato Grosso do Sul.

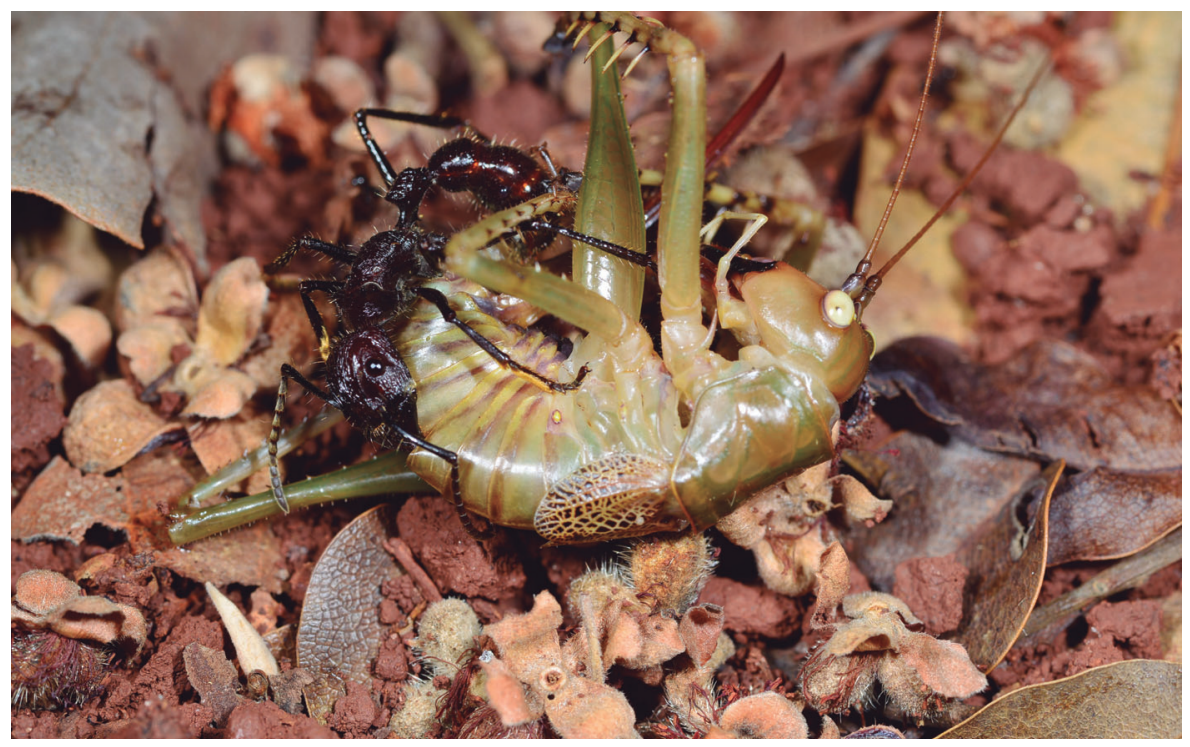

forrageando na mesma isca, ao mesmo tempo, o que pode caracterizar algum tipo de recrutamento.

O tempo médio para as Dinoponera localizarem as iscas na Caatinga foi longo (38 minutos).

\section{Paraponera clavata}

Foi observada no campus da UFMS, Campo Grande, MS e em outras observações esporádicas no Pantanal (Serra do Amolar). Os ninhos populosos são construídos no pé da árvore e a espécie tem comportamento agressivo. Foi observada quatro vezes e, em uma delas, dominou a isca de sardinha, sendo agressiva; e em outra oportunidade, foram visitantes exclusivos da isca de mel na vegetação. Na entrada do ninho foi observado que as Paraponera coletam uma grande quantidade de itens vegetais como pequenos gravetos, flores e pequenos frutos secos. Em uma isca feita com um gafanhoto imobilizado, as Paraponera recrutaram vários indivíduos e picotavam o gafanhoto no momento em que foram atacadas por Pheidole gertrudae Forel, 1886. Registramos várias mordidas das 
Pheidole nas antenas e pernas das Paraponera e várias respostas à agressão foram observadas, principalmente o comportamento de agitar as pernas tentando expulsar as Pheidole, mas mesmo assim não abandonaram o gafanhoto e o transportaram aos pedaços para o ninho, sendo seguidas até a porta do ninho por operárias de P. gertrudae (Figuras 14.5 e 14.6).

\section{Ectatomma brunneum}

Foi observada cinco vezes e não dominou a isca em nenhuma oportunidade. Apresentou muita dificuldade em obter o recurso quando a isca já estava colonizada por outra espécie, mesmo apresentando muita agressividade e recrutando várias outras operárias do ninho. Chegou a matar duas operárias de Solenopsis invicta Buren, 1972 em uma isca de sardinha como resposta à agressão, mas acabou deixando a isca e evitando a interação. Em várias oportunidades foi observada patrulhando solitariamente a superfície do solo e foram as primeiras das poneromorfas a encontrar insetos como iscas (Figura 14.7), pois possuem normalmente uma densidade de ninhos grande no Cerrado. Têm preferência em patrulhar áreas abertas.

FIGURA 14.6 - Paraponera clavata interagindo agressivamente com Pheidole gertrudae (operárias pequenas) no solo do Cerrado em Mato Grosso do Sul ao predar o Orthoptera mostrado na figura 14.5 .

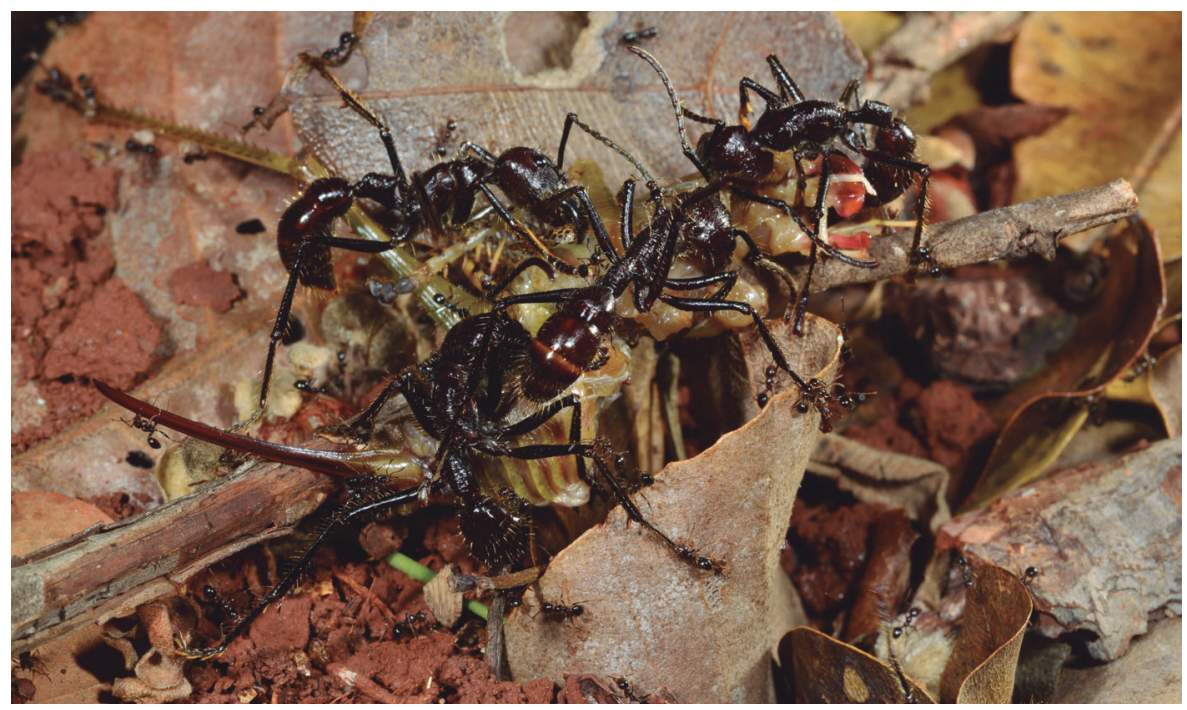

FIGURA 14.7 - Ectatomma brunneum transportando gafanhoto utilizado como isca atrativa no solo da RPPN Cara da Onça, Mato Grosso do Sul

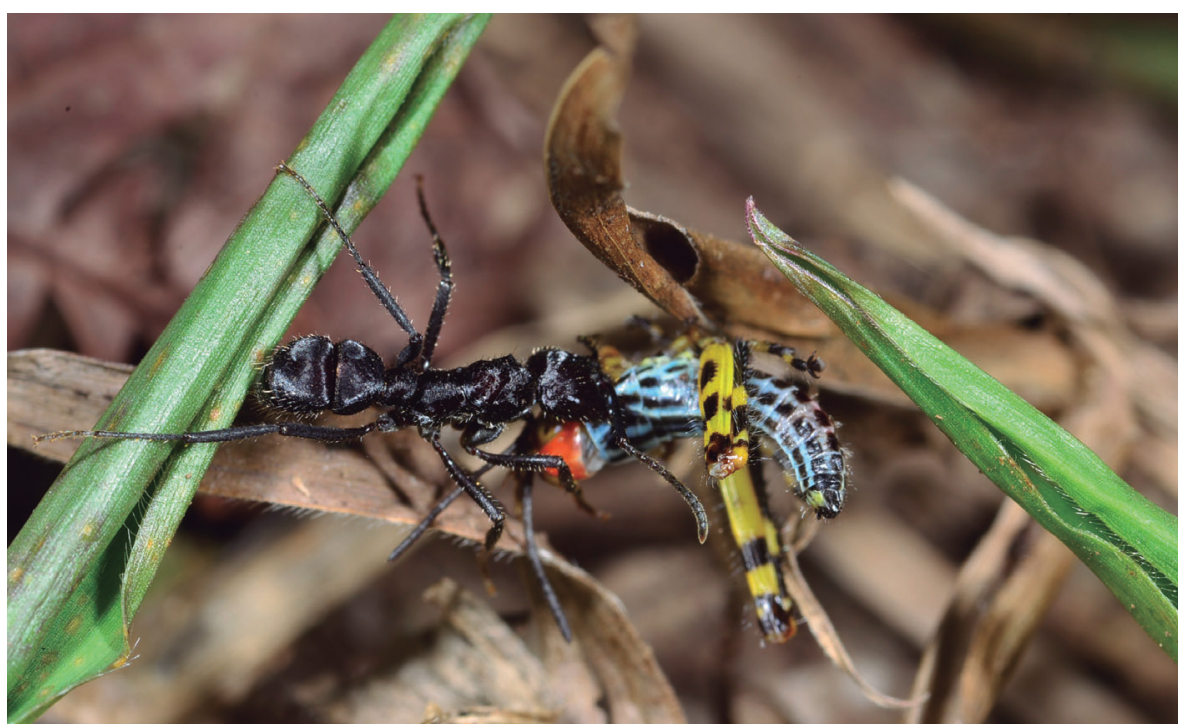




\section{Ectatomma edentatum}

Apresentou comportamento parecido com E. permagnum. Sua distância média percorrida da isca ao ninho foi calculada na Caatinga $(3,2 \mathrm{~m})$, com uma velocidade média calculada de $0,6 \mathrm{~cm} / \mathrm{s}$, porém o tempo médio para localizar as iscas foi longo (23 minutos). Frequentou a mesma isca que Dinoponera quadriceps, mas não ao mesmo tempo.

Não dominou a isca em nenhuma oportunidade e foi impedida de acessar a sardinha em duas observações no Cerrado. É uma espécie com alta frequência de visitação a iscas, mas com abundância sempre baixa (Figura 14.8).

\section{Mayaponera constricta}

Foi registrada duas vezes em iscas na Serra da Bodoquena (Figura 14.14). Na primeira vez, evitou a interação agressiva com outras espécies presentes na isca, ficando na borda do papel e esperando o melhor momento para entrar na arena, coletar um pedaço de sardinha e se afastar rapidamente. Uma minhoca morta foi primeiramente atacada por único exemplar de Mayaponera constricta (Figura 14.9), sendo que a abandonou e algum tempo depois (sete minutos), D. australis levou este alimento para o ninho.

\section{Neoponera apicalis}

Foi observada em campo somente em duas oportunidades, com um comportamento oportunista na obtenção de recursos de curta duração como um inseto morto (Figuras $14.10 \mathrm{e}$ 14.11), mas não foi observada interagindo agressivamente com outra espécie. Visitou uma única isca, onde retirou um pedaço da sardinha e saiu rapidamente.

\section{Neoponera villosa}

Tem o hábito de forragear solitariamente no solo e na vegetação com recrutamento do tipo tandem running (Figuras 14.12 e 14.13). Foi registrada em quatro oportunidades tentando chegar à isca de sardinha já dominada por outras espécies. Foi agredida e excluída da isca em duas oportunidades por Solenopsis saevissima e por Dorymyrmex sp. que empregou defesa química. Nas observações na Serra da Bodoquena, os indivíduos desciam da árvore para chegar à isca no solo. A maior atividade desta espécie observada foi ao anoitecer.

\section{Neoponera obscuricornis}

Foi observada em 15 ocasiões, nunca dominou a isca, principalmente por apresentar um fluxo esparso de visitantes; geralmente chegavam sozinhas à isca e praticamente "roubavam" um pedaço de sardinha; poucas vezes foi impedida de atingir o alimento, sendo excluída apenas em duas oportunidades por Camponotus rufipes e Solenopsis saevissima; nestas oportunidades, as espécies agrediram com mordidas as operárias de $N$. obscuricornis que tentavam chegar à fonte de alimento.

FIGURA 14.8 - Ectatomma edentatum indo em direção à isca na Flona Contendas do Sincorá, BA

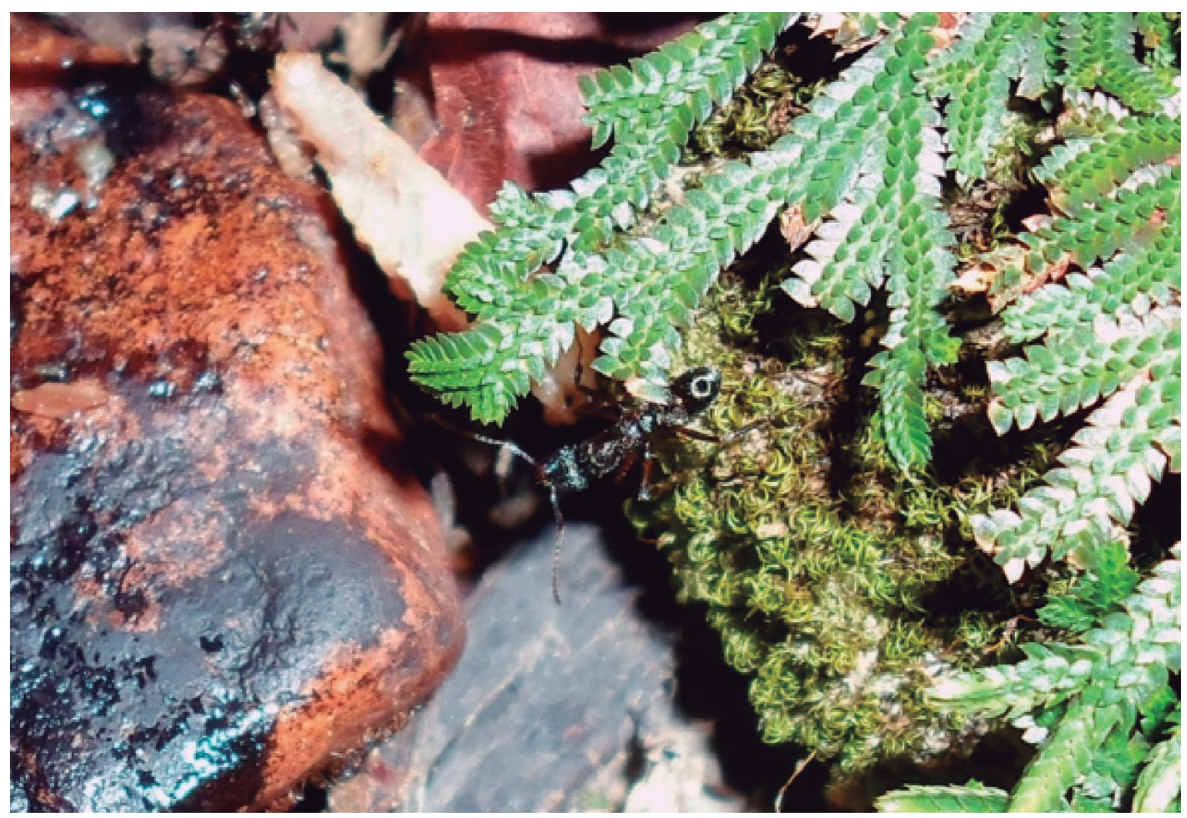


FIGURA 14.9 - Mayaponera constricta arrastando um anelídeo na Serra da Bodoquena, MS.

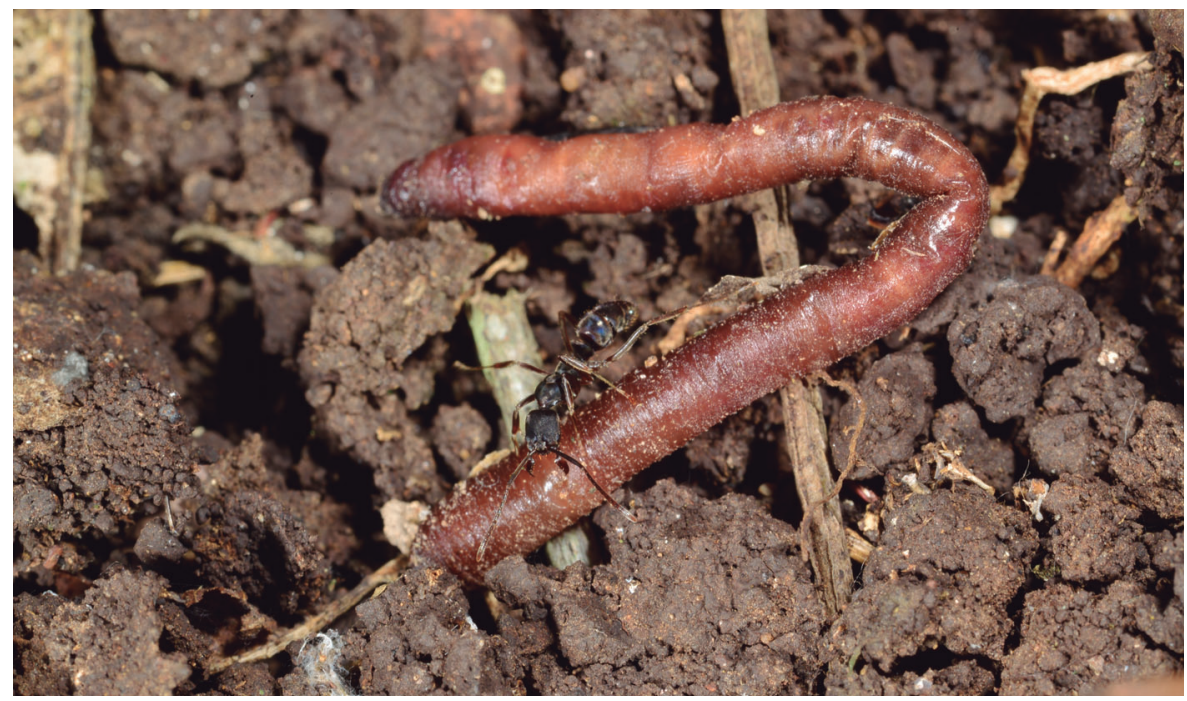

FIGURA 14.10 - Neoponera apicalis carregando um Vespidae na Mata Atlântica da Bahia.

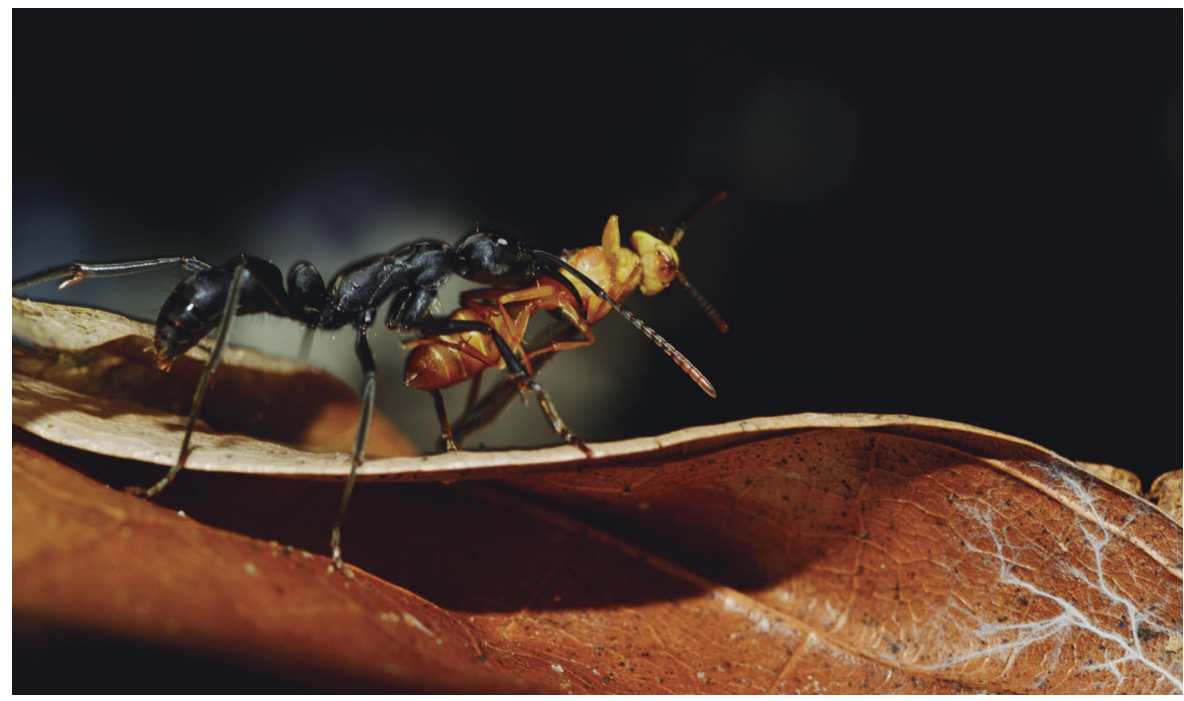

FIGURA 14.11 - Neoponera apicalis carregando um cupim na Mata Atlântica da Bahia.

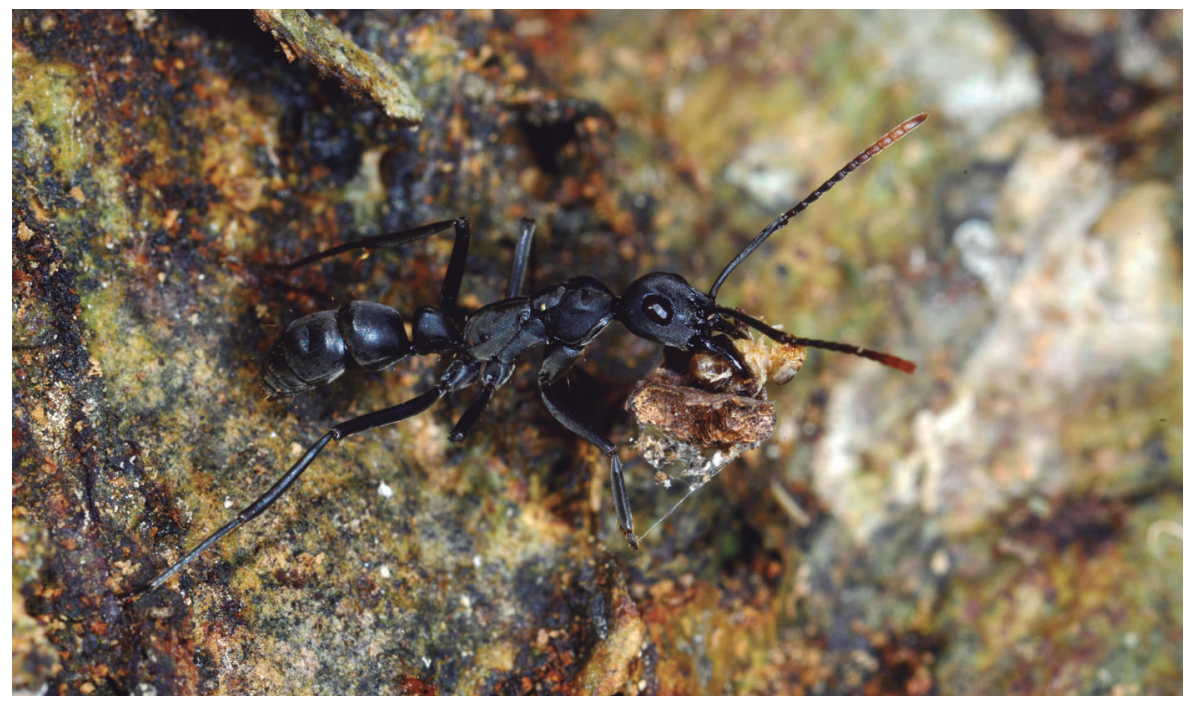


FIGURA 14.12 - Neoponera villosa em comportamento de tandem running no Cerrado de Mato Grosso do Sul.

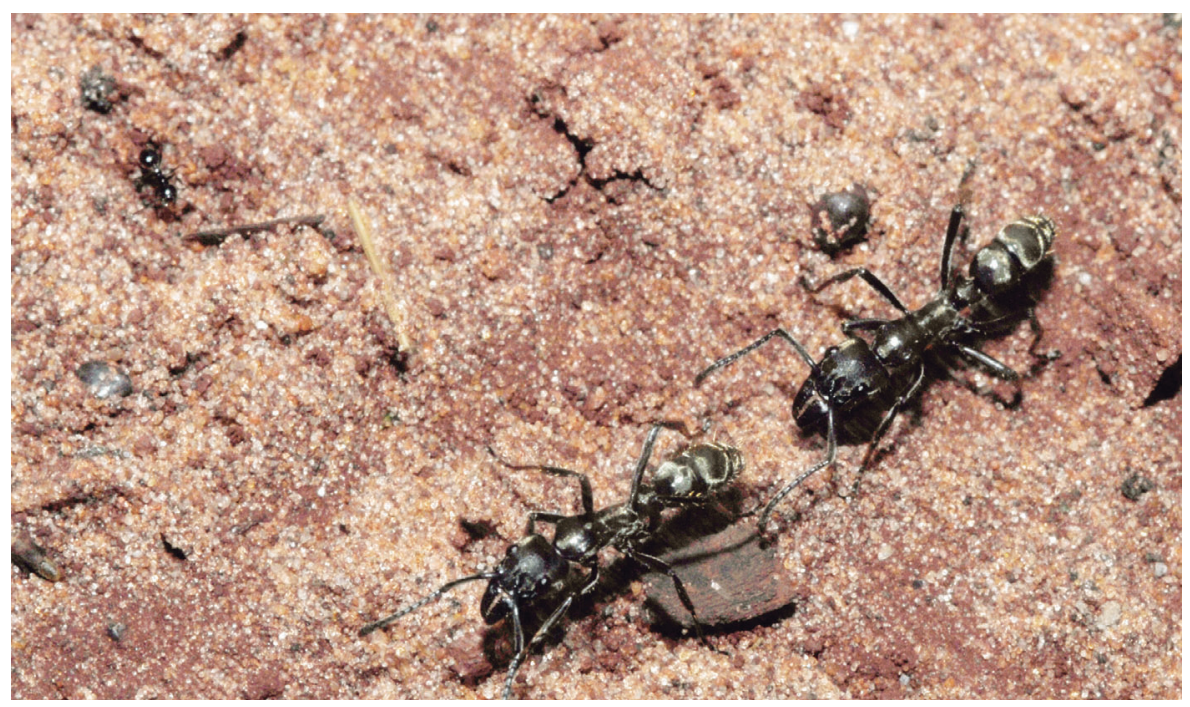

FIGURA 14.13 - Neoponera villlosa transportando fragmento vegetal na Mata Atlântica da Bahia.

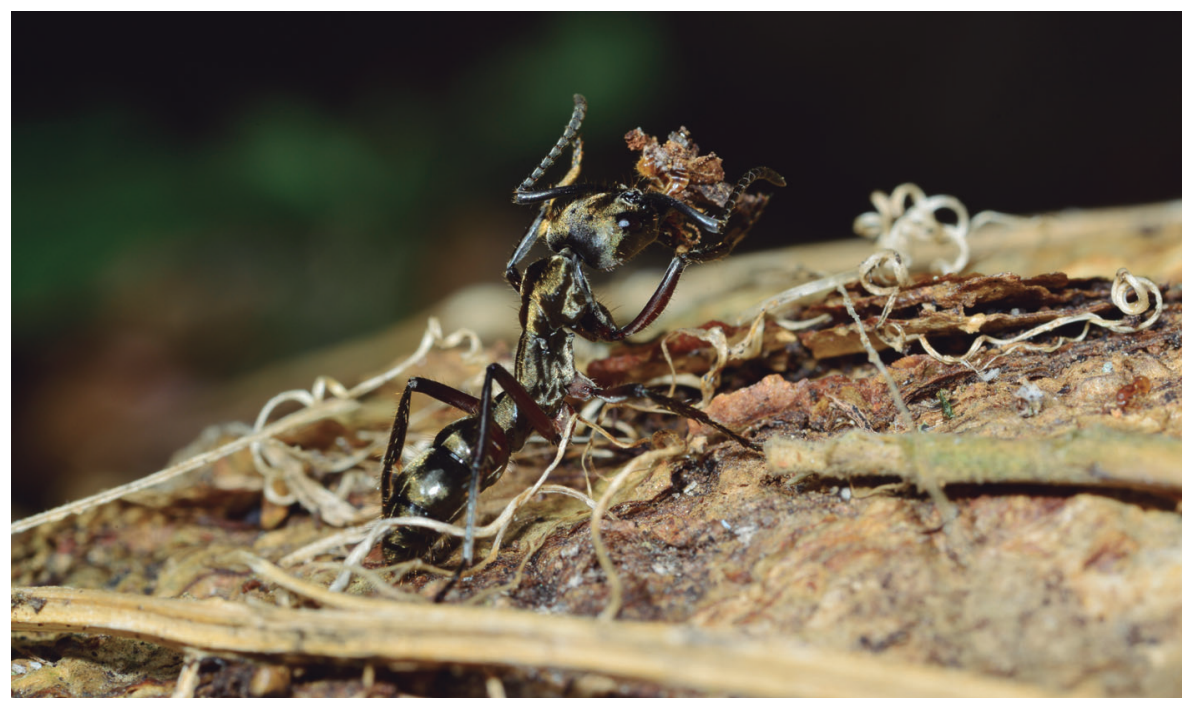

FIGURA 14.14 - Mayaponera constricta na entrada do ninho na RPPN Cara da Onça, Serra da Bodoquena, MS.

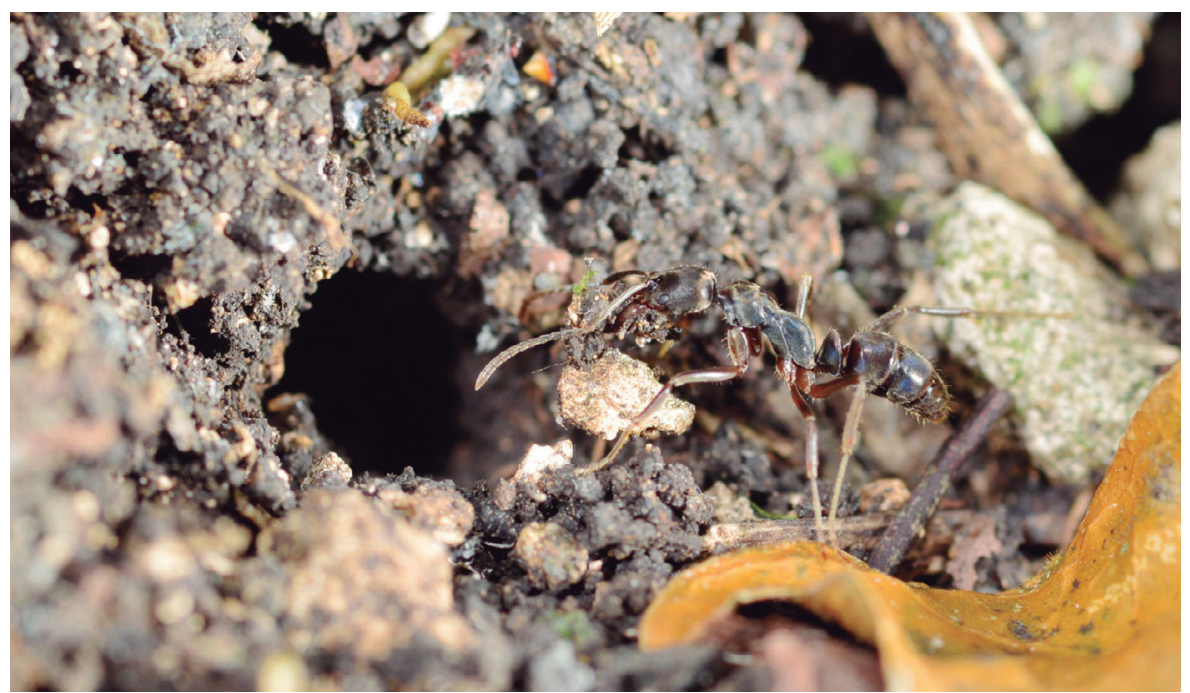




\section{Odontomachus haematodus}

Foi agressiva em duas oportunidades das quais interagiu com outras espécies; chegando a dominar um lambari que foi colocado próximo à entrada do ninho, mordendo e excluindo operárias de Forelius (Figura 14.15). Vários indivíduos tentaram arrastar o lambari para o ninho e depois de um longo tempo de tentativas abandonaram a isca, que já estava sendo visitada por vários outros insetos.

Em uma isca de sardinha, O. haematodus interagiu agressivamente com Pheidole sp. matando vários indivíduos com as mandíbulas na tentativa de expulsá-los da sardinha, mas o recrutamento das Pheidole foi intenso e várias operárias maiores atacavam as Odontomachus que eram impedidas de continuarem na isca, mas permaneciam próximas sem desistir; conseguindo ter acesso em alguns momentos apenas pela parte de baixo do papel. A diferença notada do comportamento desta espécie em relação à maioria das poneromorfas observadas é que ela tenta dominar o recurso, não se "contentando" em retirar pedaços e levar ao ninho.

\section{Considerações finais sobre as interações observadas}

As espécies epigeicas de Ponerinae, Ectatomminae e Paraponerinae parecem estabelecer nitidamente seus territórios, reconhecendo os seus inimigos que estão no mesmo espaço morfofuncional, desta forma evitando o contato e a disputa na fonte de alimento, ou seja, reconhecem o seu "inimigo íntimo".

FIGURA 14.15 (A e B) - Odontomachus haematodus forrageando num cadáver de lambari e interagindo com moscas e com Forelius sp. na RPPN Cara da Onça, Serra da Bodoquena, MS

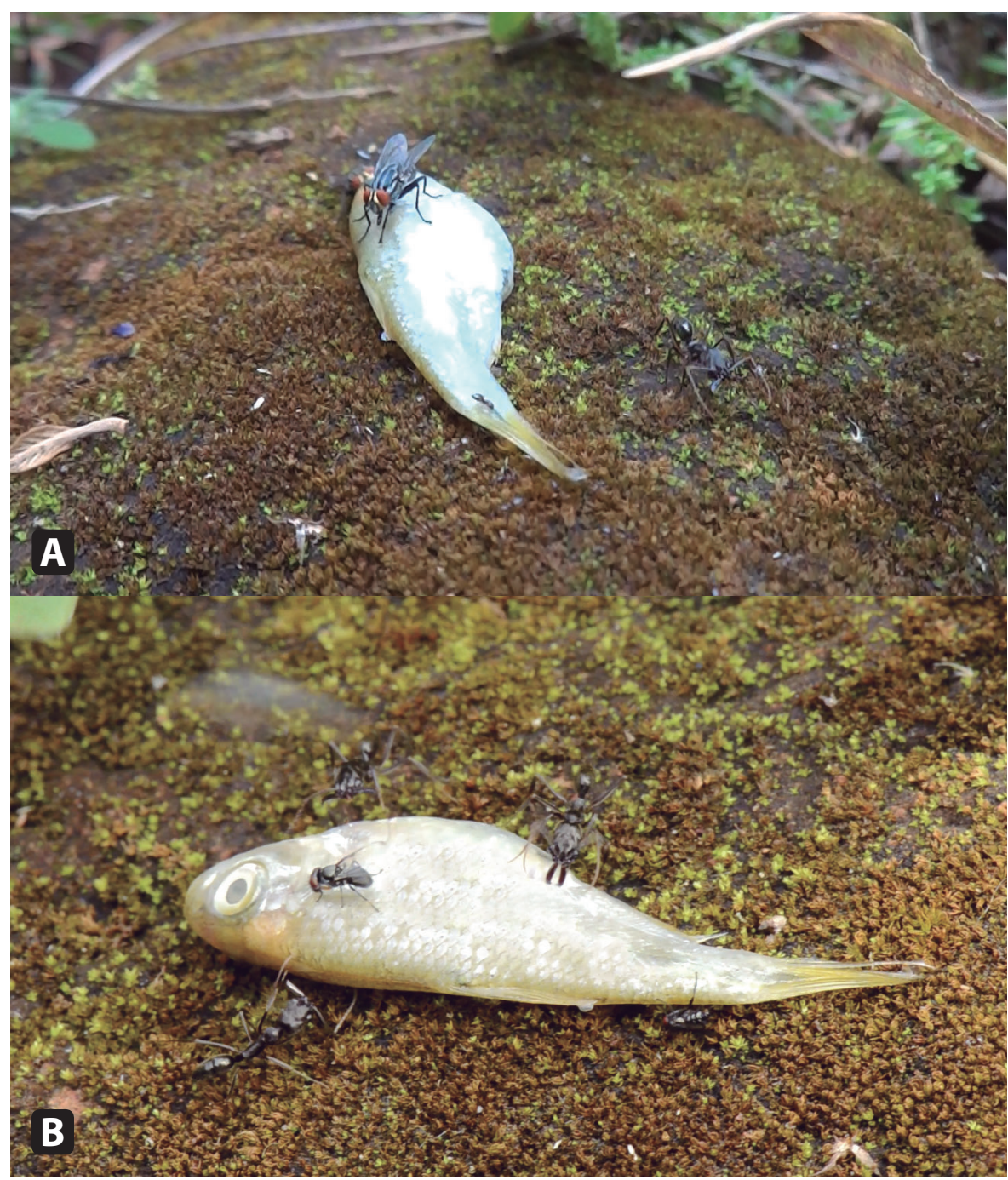


Nossas observações, mesmo com um alto grau de antropomorfismo, focadas em formigas poneromorfas, indicam que as interações competitivas ocorrem com frequência em iscas atrativas e que muitas vezes a fonte de alimento é dominada por espécies que possuem uma estratégia de recrutamento massivo dos clados Myrmicinae, Formicinae, Dolichoderinae e Dorylinae; contudo esta dominância não impede que as formigas poneromorfas tenham acesso ao recurso, dependendo da qualidade e quantidade disponível e da persistência deste recurso na área de forrageamento da espécie.

A diversificação na dieta das formigas poneromorfas induz à sobreposição de nicho, o que, em ambientes tropicais com alta heterogeneidade espacial, permite a coexistência de diferentes estratégias de compartilhamento de recursos.

A maioria dos Poneroides de forrageamento solitário evitam interações agonísticas, com exceção de algumas espécies que realizam forrageamento em grupo (O. bauri, O. haematodum, Ectatomma brunneum) que são capazes de despender bastante tempo em conflitos com outras espécies.
De uma forma geral, as poneromorfas não excluem e nem são excluídas permanentemente da fonte de alimento, não são forrageadores exclusivos de um determinado território e sobrepõem seus nichos espaciais e tróficos com espécies de outras guildas.

Concluímos que em ambientes tropicais não existe uma pré-estabelecida hierarquia de dominância, como reportada em outros ambientes; e que um número muito grande de variáveis ecológicas, fisiológicas e espaciais está influenciando as interações competitivas interespecíficas envolvendo formigas poneromorfas.

\section{Agradecimentos}

Agradecemos aos editores deste volume pelo convite para contribuirmos com este capítulo. Agradecemos aos proprietários da RPPN Cara da Onça, da Fazenda Santa Carlota, Cajuru- SP e aos núcleos Estação Ecológica Jataí, Luis Antônio- SP e Flona Contendas do Sincorá, Bahia. Tivemos apoio da FAPESP, CAPES, CNPq, ICMBio e do Programa Pronex $\mathrm{CNPq} /$ Fapesb. Agradecemos também o apoio do grupo de pesquisa do Hecolab "Ejército de Liberación de la naturaleza". 
APÊNDICE 14.1 - Transcrição de um protocolo de observação realizado com isca de sardinha no Cerrado, com registros de comportamento da espécie Odontomachus chelifer feitos no campo, para ilustrar uma das formas de obtenção das informações e a dinâmica da disputa pelo recurso nas interações interespecíficas.

\author{
Observação número 33 \\ Local: Cerrado de Cajuru \\ Horário: 10:15h \\ Tempo: 90 minutos
}

“....Após 7 minutos de exposição da isca de sardinha uma Odontomachus enorme marron brilhante chega lentamente pelo lado oeste da isca, já colonizada por uma Pheidole escura. Ela toca as antenas na sardinha, depois limpa a antena com as pernas anteriores, coleta um pedaço pequeno de sardinha e sai bem devagar pelo mesmo lado que entrou. Neste momento outra Pheidole pequenininha, recrutando outras operárias, entra por baixo do papel.....(10:46h) A Odontomachus se aproxima da isca novamente, as operárias de Pheidole percebem a sua presença e tentam atacá-la, mas ela não foge e responde às agressões avançando sobre as Pheidole. A Odontomachus coletou um pedaço de sardinha bem grande desta vez e voltou para o ninho e as Pheidole (mais ou menos 20 indivíduos presentes na isca) não conseguiram impedi-la.... (11:00h) A Odontomachus se aproxima novamente, mas desta vez foi interceptada no folhiço já pelas inúmeras Pheidole que chegavam na isca. Uma Camponotus preta sobe no papel neste momento, houve muitos encontros e agressões até desistir e sair da isca....(11:02h) A Camponotus sobe na isca retira um pedaço e sai rapidamente, enquanto a Odontomachus é impedida de chegar na sardinha novamente.....As Pheidole pequenininhas aumentam o seu fluxo por debaixo da isca e formam uma trilha bem definida de forrageamento com dezenas de operárias.... (11:05h) A Odontomachus se encontra com a Camponotus sobre a isca e ambas se agridem, cada uma saindo para um lado. Uma outra Odontomachus (O. bauri) chega pelo lado norte da isca, chegou a pegar um pedaço da sardinha mas foi atacada pelas Pheidole, deixando o pedaço e fugindo da isca, mas ainda permanecendo por perto observando a movimentação... (11:19h) Uma operária de saúva sobe na isca pelo lado Norte e não é agredida pelas Pheidole...duas Odontomachus estão próximas da isca tentando achar uma forma de ter acesso a sardinha...(11:22h) A Odontomachus marrom grande (chelifer) consegue retirar um pedaço bastante grande de sardinha e sair sem sofrer ataques....(11:27h) A saúva agora levou uma mordida na perna de um Pheidole enquanto tentava arrancar um pedaço do papel higiênico que está a sardinha, deixou a isca sem levar nada.... (11:41h) Uma Cephalotes sobe na isca e foi atacada imediatamente, um soldado de Atta também é atacado pelas Pheidole, mas decide avançar sobre as Pheidole que se espalham na isca. A Atta fica em posição levantada como se tivesse percebido que haveria briga....neste momento uma vespa Myschocyttarus pousa na isca e espanta várias operárias. Ao final do período de observação as formigas foram capturadas para posterior identificação. Sete espécies interagiram nesta isca sendo na seguinte ordem de visitação: Pheidole oxyops (dominou a porção superior da isca), Odontomachus chelifer, Pheidole sp. 7 (dominou a porção ventral da isca), Camponotus (Myrmaphaenus) sp.1, Odontomachus bauri, Camponotus sp. 2, Atta sexdens rubropilosa e Cephalotes pusillus. 


\section{REFERÊNCIAS}

ANDERSEN A.N. 1986. Patterns of ant communities organization in mesic southeastern Australia. Australian Journal of Ecology, 3: 87- 97.

ARAÚJO A.; ZENILDE Z. 2006. Foraging behavior of the queenless ant Dinoponera quadriceps Santschi (Hymenoptera: Formicidae). Neotropical Entomology, 35(2):159-164.

BERNSTEIN R.A. 1975. Foraging strategies of ants in response to variable food density. Ecology, 56: 213-219.

BRANDÃO C.R.F, SILVESTRE R.; REIS-MENEZES A. A Influência das interações comportamentais entre espécies de formigas em levantamentos faunísticos em comunidades de Cerrado. Ecologia e Comportamento de Insetos. Oecologia australis, vol. 8. Disponível em http://www.oecologiaaustralis.org/ojs/index.php/oa/ issue/view/8.

BREED M.D., FEWELL J.H., MOORE A.J.; WILLIAMS K.R. 1987. Graded recruitment in a ponerine ant. Behaviour Ecology and Sociobiology, 20: 407-411.

DOBZHANSK T. 1950. Evolution in the Tropics. American Scientist, 38: 209-221.

EDELSTEIN-KESHET L., WATMOUGH J.; ERMENTROUT G.B. 1995. Trail following in ants: individual properties determine population behaviour. Behaviour Ecology and Sociobiology, 36:119 133.

EHMER B.; HÖLLDOBLER B. 1996. Foraging behavior of Odontomachus bauri on Barro Colorado Island, Panama. Psyche, 102: 215-224.

FEWELL J.H., HARRISON J.F., LIGHTON J.R.B.; BREED M.D. 1996. Foraging energetics of the ant Paraponera clavata. Oecologia, 105: 419-427.

GIANNOTTI E.; MACHADO V.L.L. 1992. Notes on the foraging of two species of ponerine ants: food resources and daily hunting activities (Hymenoptera, Formicidae). Bioikos, 6: 7-17.

GOMES L., DESUÓ I. C., GOMES G.; GIANNOTTI E. 2009. Behavior of Ectatomma brunneum (Formicidae: Ectatomminae) preying on dipterans in field conditions. Sociobiology, 53(3): 913-926.

GREENSLADE P.J.M. 1982. Competition and Community Organization in an Australian Ant Fauna. The biology of social insects. Proc. 9th Congr. IUSSI. M. D. Breed, C. D. Michener and H. E. Evans. Boulder, Westview Press: 65p.
GUÉNARD B.; SILVERMAN J. 2011. Tandem carrying, a new foraging strategy in ants: description, function, and adaptive significance relative to other described foraging strategies. Naturwissenschaften, 98(8): 651-659.

HAGEN K.S., DABB R.H.; REESE J. 1984. The food of insects. In: Huffaker C.B.; Rabb R.L. (eds.) Ecological Entomology. New York, John Wiley and Sons, p. 79-112.

HÖLLDOBLER B. 1987. Communication and competition in ant communities. In S. Kawano, J.H. Connel; T. Hidaka (eds.), Evolution and Coadaptation in Biotic Communities. Tokyo University Press, p. 95-124.

HÖLLDOBLER B.; WILSON E.O. 1990. The Ants. Cambridge, Belknap/Harvard University Press. 732p.

HUNT J.H. 1974. Temporal activity patterns in two competing ant species (Hymenoptera: Formicidae). Psyche, 8(2): 237-242.

LEVINGS S.C. 1983. Seazonal, annual and among-site variation in the ground ant community of a deciduous tropical forest. Ecological Monographs, 53(4): 435-455.

LEVINGS S.C.; TRANIELLO J.F.A. 1981. Territoriality, nest dispersion, and community structure in ants. Psyche, 88: 265-319.

\section{LIMA L.D.; ANTONIALLI-JUNIOR W. 2013.}

Foraging strategies of the ant Ectatomma vizottoi (Hymenoptera, Formicidae). Revista Brasileira de Entomologia, 57(4): 392-396.

MEDEIROS F.N.S.; OLIVEIRA P.S. 2009. Seasondependent foraging patterns. Case study of a Neotropical forest-dwelling ant (Pachycondyla striata, Ponerinae). In: Stefan Jarau; Michael Hrncir (eds.). Food Exploitation by Social Insects: Ecological, Behavioral, and Theoretical Approaches. Boca Raton: Taylor; Francis Group, p. 81-95.

MOUTINHO P.R.S. 1991. Note on foraging activity and diet of two Pheidole Westwood species (Hymenopotera: Formicidae) in an area of "shrub canga” vegetation in Amazonian Brazil. Revista Brasileira de Biologia, 51(2): 403-406.

MORRISON L.W. 2000. Mechanisms of interspecific competition among an invasive and two native fire ants. Oikos, 90: 238-252.

OVERAL, W.L. 1986. Recrutamento e divisão de trabalho em colônias naturais da formiga Ectatomma quadridens (Fabr.) (Hymenoptera: Formicidae: Ponerinae). Boletim do Museu Paraense Emílio Goeldi, Série Zoologia, 2: 113-135. 
PASSERA L.; ARON S. 2006. Les Fourmis: Comportement, Organisation Sociale et Évolution. CNRC-NRC press. Ottawa. 480p.

PETAL J. 1978. The role of ants in ecosystems. In: Brian, M. V. (ed.) Production Ecology of Ants and Termites. Cambridge, Cambridge Univ. Press 409 p.

PIE M.R. 2004. Foraging ecology and behaviour of the ponerine ant Ectatomma opaciventre Roger in a Brazilian savannah. Journal of Natural History, 38: 717-729.

RAIMUNDO R.L.G., FREITAS A.V.L.; OLIVEIRA P.S. 2009. Seasonal patterns in activity rhythm and foraging ecology in the Neotropical forest-dwelling ant, Odontomachus chelifer (Formicidae: Ponerinae). Annals of the Entomological Society of America, 102(6): 1151-1157.

SILVESTRE R. 1995. Levantamento da Fauna de Formigas de uma Mancha de Cerrado no Estado de São Paulo e Observações Sobre a Dinâmica de Visitação às Iscas. Ribeirão Preto, SP. FFCL-USP. 141 p. (Dissertação de Mestrado).
TORRES J.A. 1984. Niches and coexistence of ant communities in Puerto Rico: repeated patterns. Biotropica, 16(4): 284-295.

TOFOLO V.C., GIANNOTTI E., MOLEIRO H.R.; SIMÕES M.R. 2011. Diet and spatial pattern of foraging in Ectatomma opaciventre (Hymenoptera: Formicidae) in an anthropic area Sociobiology, 58(3): 607-619.

TRANIELLO J.F.A. 1989. Foraging strategies of ants. Annual Review of Entomology, 34: 191-210.

ZINCK L., HORA R.R., CHÂLINE N.; JAISSON

P. 2008. Low intraspecific aggression level in the polydomous and facultative polygynous ant Ectatomma tuberculatum. Entomologia Experimentalis et Applicata, 126: 211-216. 